九州大学学術情報リポジトリ

Kyushu University Institutional Repository

\title{
NUMERICAL TABLES OF OPTIMUM SEQUENTIAL DESIGNS BASED ON MARKOV CHAINS FOR SELECTING ONE OF TWO MEDICAL TREATMENTS
}

Goto, Masashi

Shionogi Computing Center, Shionogi Research Laboratory

Sugimura, Masahiko

Institute of Applied Mathematics, Kobe University of Mercantile Marine

Asano, Choichiro

Shionogi Computing Center, Shionogi Research Laboratory

https://doi.org/10.5109/13051

出版情報: 統計数理研究. 14 (3/4)，pp. 27-56，1971-03. Research Association of Statistical Sciences

バージョン :

権利関係 : 


\title{
NUMERICAL TABLES OF OPTIMUM SEQUENTIAL DESIGNS BASED ON MARKOV CHAINS FOR SELECTING ONE OF TWO MEDICAL TREATMENTS
}

\author{
By \\ Masashi Goto*, Masahiko SugIMURA** \\ and \\ Chooichiro Asano*
}

(Received January 14, 1971)

\section{Introduction and principle of problem}

The present problem is to determine an optimum statistical procedure in choosing one of two populations in the light of observations.

We are now faced to decide a superior medical treatment in two, on a minimum number of patients from an ethical point of view. In such situations, since we cannot give any probability of two kinds of decision errors a priori, this is not merely a problem of applying usual sequential tests, but also is to make a new type of sequential test in order to give an optimum plan for medical trials.

The assumptions are prepared throughout this paper as follows.

(1) There are $N$ patients to be treated with one of the two treatments, $A$ or $B$. The effective proportions of the two treatments are unknown to us and denoted by $p_{A}$ and $p_{B} . \quad N$ is fixed and large.

(2) We suppose that the clinical trial is performed sequentially on pairs of two patients drawn from the $N$ patients, administrating the treatment $A$ on a patient and $B$ on the other.

(3) If such sequential clinical trials are terminated, one treatment is decided to be superior to the other, and the selected treatment will be applied on all of the remaining patients.

Let us now define a discrepancy function $p$ between $p_{A}$ and $p_{B}$ as follows,

$$
p=\frac{p_{B}\left(1-p_{A}\right)}{p_{B}\left(1-p_{A}\right)+p_{A}\left(1-p_{B}\right)},
$$

where $p$ is a binomial parameter of double dichotomies based on odds ratios. Then $p=0.5$ is critical in a sense that if $p<0.5$ then treatment $A$ is selected and otherwise treatment $B$ is selected as a superior one.

Therefore, according to the decision procedure defined above, the expected loss

* Shionogi Computing Center, Shionogi Research Laboratory.

** Institute of Applied Mathematics, Kobe University of Mercantile Marine. 
is shown as

E LOSS $=G \cdot|p-0.5| \cdot\left[E(n)+\{N-2 E(n)\} \cdot P_{r}(\right.$ Selecting Inferior $\left.)\right]$

on the number of patients treated with the inferior treatment in an ethical sense, where $G$ is a proportional constant and $E(n)$ is an expected number of pairs sequen. tially observed.

Now we assume an a priori distribution of $p$ with a density function $f(p)$.

Then our criterion of optimum sequential plans is to minimize the average risk (or the over-all expected loss) $\overline{\text { E LOSS }}$ over the a priori distribution $f(p)$.

In such decision theoretical situation of medical sequential plans, Armitage [1], [2], Colton [5], Choi [4], and Sugimura-Asano [7] [15] have partially discussed and constructed some types of sequential plans. Furthermore, the authors recently presented the whole formulation and properties in a category proposed by them, which may be published in Ann. Inst. Stat. Math..

The purpose of this paper, therefore, is to give the available tables and figures computed by a FACOM $270-30$ and to discuss further details for the practice with some summarized results of the above paper.

\section{Definitions, formulations and the results}

\subsection{Open type.}

The open type introduced here is shown in Fig. 1 and is just like in SugimuraGoto-Asano [16], [17]. Both acceptance regions $A$ and $B$ are given by the outsides of horizontal lines at an assigned integer $\pm c$ of favorable pairs of $A$ or $B$. The middle region is to be still continued the clinical trial.

For example, a sequence of results of favorable pairs observed, i. e., $(B, B, A, B$, $B, A, B, B)$ is plotted in Fig. 1. The figure illustrates consequently accepting $B$ as the preference.

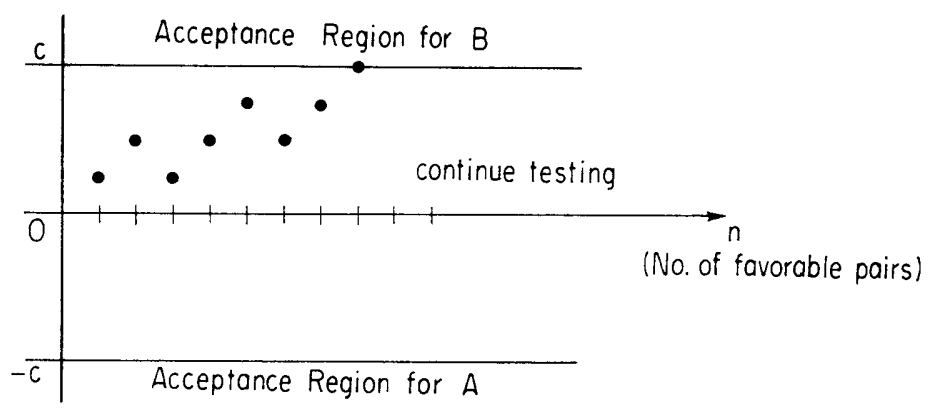

Fig. 1. Sequential procedure for an open type $(c=4)$.

Then two kinds of probability of acceptance $A$ or $B, \alpha_{1}^{*}(p)$ and $\alpha_{3}^{*}(p)$ in this plans are obtained as follows.

(2) $\quad \alpha_{1}^{*}(p)=\lim _{j \rightarrow \infty} P_{r}\left\{\begin{array}{l}\text { the sequential test terminates and accepts } B \\ \text { at the }(c+2 j) \text { th sampling step }\end{array}\right\}$ 


$$
=p^{c}+\left\{\sum_{k=1}^{c-1}\left(\begin{array}{l}
c \\
k
\end{array}\right) p^{c+k} q^{k} D_{(c-k-1)}\right\} / D_{(c-1)},
$$

where $q=1-p,\left(\begin{array}{l}c \\ k\end{array}\right)$ indicates a possible number of drawing $k$ things from $c$,

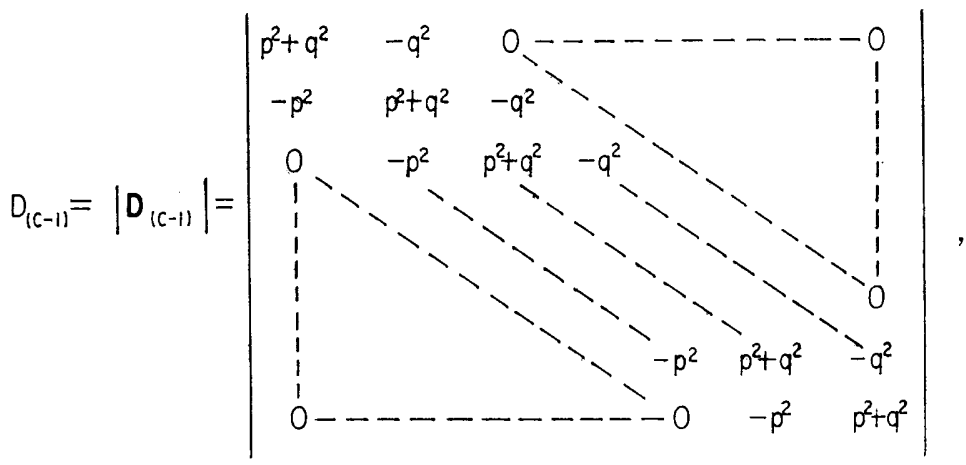

(4) $\quad D_{(0)} \equiv 1$, and

$$
D_{(h)}=\left(p^{2}+q^{2}\right) D_{(h-1)}-p^{2} q^{2} D_{(h-2)} \quad(h=2,3, \cdots, c-1) .
$$

In the same manner, we obtain that

$$
\begin{aligned}
\alpha_{3}^{*}(p) & =\lim _{j \rightarrow \infty} P_{r \cdot} \cdot\left\{\begin{array}{l}
\text { the sequential test terminates and accepts } \\
A \text { at the }(c+2 j) \text { th sampling step }
\end{array}\right\} \\
& =q^{c}+\left\{\sum_{k=1}^{c-1}\left(\begin{array}{l}
c \\
k
\end{array}\right) p^{k} q^{c+k} D_{(c-k-1)}\right\} / D_{(c-1)} \\
& =1-\alpha_{1}^{*}(p) .
\end{aligned}
$$

Furthermore, the average sampling favorable pair number $\mathrm{ASN}, E(n \mid p, c)$ or $E(n)$, is given as follows,

(6) $E(n \mid p, c)=c+\sum_{i=1}^{c-1} \sum_{j=1}^{c-1} s_{i+1} a_{i j}$,

where $a_{i j}$ shows the $(i, j)$ element of an inverse matrix $\boldsymbol{D}_{(c-1)}^{-1}$

(7) $D_{(c-1)}^{-1}=\frac{1}{D_{(C-1)}}$

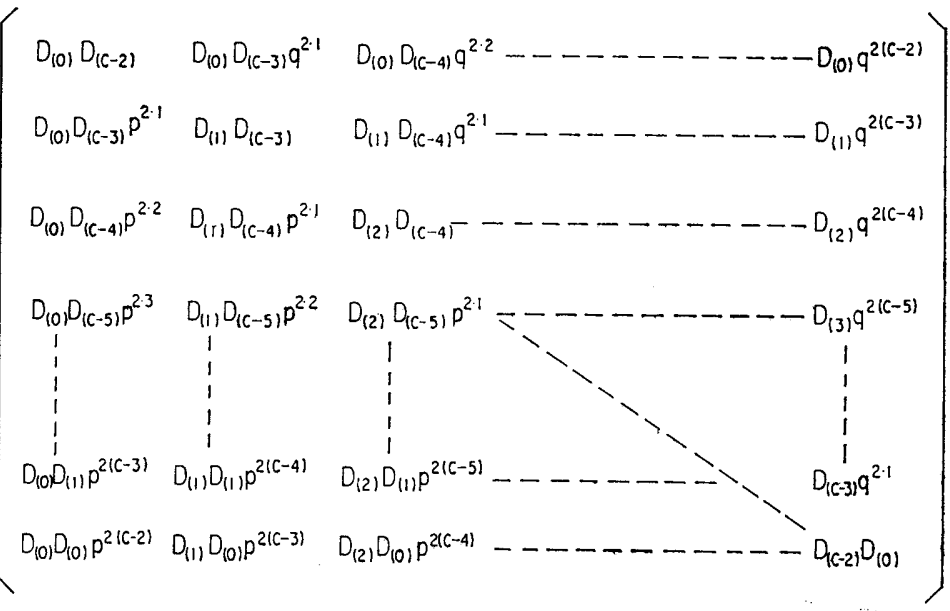


and

(8)

$$
s_{i+1}=\left(\begin{array}{c}
c \\
i
\end{array}\right) p^{c-i} q^{i} \quad(i=1,2, \cdots, c-1) .
$$

By using (2), (5) and (6), the over-all expected loss function is expressed under an a priori distribution $f(p)$ for $p$ as follows.

$$
\begin{aligned}
\overline{\text { E LOSS } / N G=} & \int_{0.5}^{\Delta_{2}}(p-0.5) f(p) d p+\int_{\Delta_{1}}^{\Delta_{2}}(0.5-p) \cdot \alpha_{1}^{*}(p) \cdot f(p) \cdot d p \\
& +-\frac{1}{N} \int_{\Delta_{1}}^{\Delta_{2}}(0.5-p)\left\{1-2 \alpha_{1}^{*}(p)\right\} \cdot E(n \mid p, c) \cdot f(p) \cdot d p,
\end{aligned}
$$

where the interval $\left(\Delta_{1}, \Delta_{2}\right)$ indicates a defined interval of $p$ in a priori distribution for $p$, and indicates $0<\Delta_{1} \leqq 0.5 \leqq \Delta_{2}<1$.

If $f(p)$ is a discrete type, the above integrations are replaced by adequate summations in the following way.

$$
\begin{aligned}
\overline{\mathrm{ELOSS}} / \mathrm{NG}= & \sum_{\left\{i \mid p_{i}>0.5\right\}}\left(p_{i}-0.5\right) \cdot f\left(p_{i}\right)+\sum_{\text {all } i}\left(0.5-p_{i}\right) \cdot \alpha_{1}^{*}\left(p_{i}\right) \cdot f\left(p_{i}\right) \\
& +\frac{1}{N} \sum_{\text {all } i}\left(0.5-p_{i}\right)\left(1-2 \alpha_{1}^{*}\left(p_{i}\right)\right) \cdot E\left(n \mid p_{i}, c\right) \cdot f\left(p_{i}\right) .
\end{aligned}
$$

\subsection{Closed and unwedged type of the sequential plans}

The closed and unwedged type is shown Fig. 2. The decision rule is to accept one of three hypothesis, $H_{1}: p>0.5$ (i. e., $p_{A}<p_{B}$ ), $H_{3}: p<0.5$ (i. e., $p_{A}>p_{B}$ ) and $H_{2}$ : $p=0.5$ (i. e., $p_{A}=p_{B}$ ), with an assigned $n_{t}$ pairs and the horizontal lines of both sides.

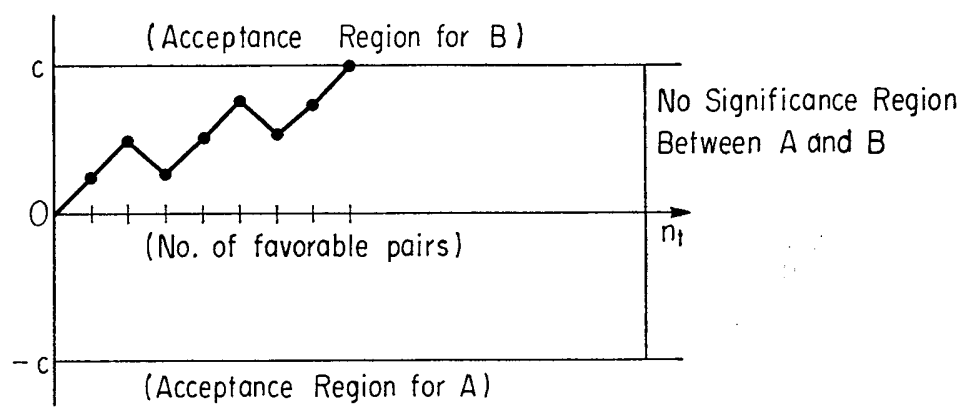

Fig. 2. Sequential procedure for a closed and unwedged type $(c=4)$.

That is to say, if the number of favorable pairs attains to the upper, or lower region, we accept the hypothesis $H_{1}$ (select $B$ ) or hypothesis $H_{3}$ (select $A$ ) and if the pass attains to the outside of $n_{t}$, we accept $H_{2}$ (no difference between $A$ and $B$ ).

Then the probability $\alpha_{i}(p)$ is given for accepting a hypothesis $H_{i}, i=1,2,3$, as follows.

$$
\begin{aligned}
& \alpha_{1}(p)=S_{0}(p) \cdot T_{2}(p)^{h} \cdot E_{1}, \\
& \alpha_{3}(p)=S_{0}(q) \cdot T_{2}(q)^{h} \cdot E_{1}, \\
& \alpha_{2}(p)=S_{0}(p) \cdot T_{2}(p)^{h} \cdot \sum_{j=2}^{c} E_{j}=1-\left\{\alpha_{1}(p)+\alpha_{3}(p)\right\},
\end{aligned}
$$


where $q=1-p, h=\left(n_{t}-c\right) / 2$, and $E_{j}$ is an elementary vector with one as the $j$-th component, $j=1,2, \cdots, c+1$, and

$$
\begin{aligned}
& S_{0}(p)=\left(s_{1}, s_{2}, \cdots, s_{c+1}\right), \\
& s_{i+1}=\left(\begin{array}{c}
c \\
i
\end{array}\right) p^{c-i} q^{i}, \quad i=0,1,2, \cdots, c,
\end{aligned}
$$

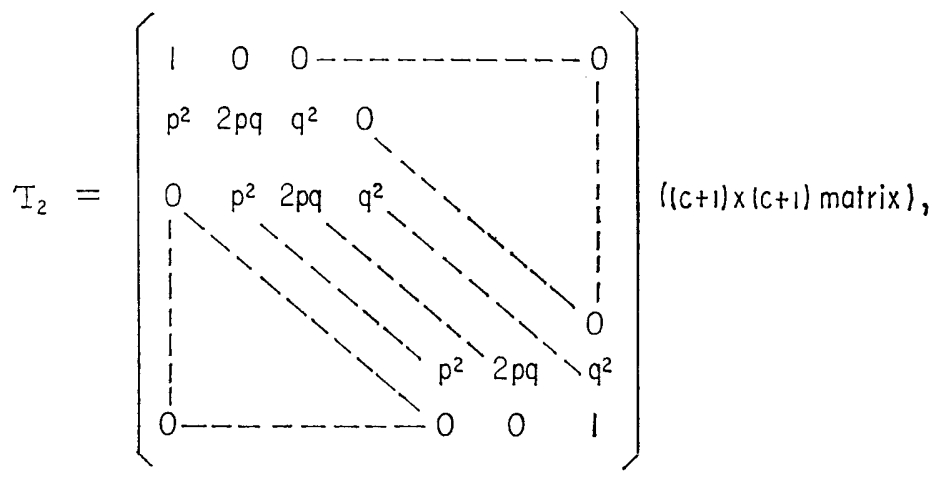

and where if $n_{t}-c$ is odd, then $\alpha_{i}\left(p ; c, n_{t}\right)=\alpha_{i}\left(p ; c, n_{t}-1\right)$, and therefore we may put $n_{t}-c$ is even without any loss of generality.

Furthermore, the average sampling number of favorable pair is as follows.

$$
E\left(n \mid p, c, n_{t}\right)=n_{t}-2 \sum_{j=0}^{h-1}\left\{S_{0}(p) \cdot T_{2}(p)^{j}+S_{0}(q) \cdot T_{2}(q)^{j}\right\} \cdot E_{1} .
$$

Now let us assume an additional assumption is that if $H_{1}$ or $H_{3}$ is accepted, then we take treatment $B$ or $A$ on the remaining $N-2 n$ patients, and if $H_{2}$ accepted, then we accept half and half $B$ and $A$ on the remaining.

Then the over-all expected loss function is given by

$$
\begin{aligned}
\overline{\mathrm{ELOSS}} / \mathrm{NG}= & \frac{1}{2}\left\{\int_{0.5}^{\Delta_{2}}(p-0.5) \cdot f(p) \cdot d p-\int_{\Delta_{1}}^{0.5}(p-0.5) \cdot f(p) \cdot d p\right\} \\
& -\frac{1}{2 N} \int_{\Delta_{1}}^{\Delta_{2}}(p-0.5)\left\{\alpha_{1}(p)-\alpha_{3}(p)\right\}\left\{N-2 E\left(n \mid p, c, n_{t}\right)\right\} \cdot f(p) \cdot d p,
\end{aligned}
$$

where $A_{1}<0.5<\Delta_{2}$. If the a priori distribution $f(p)$ is discrete, the $\overline{\mathrm{E} \text { LOSS}} / \mathrm{NG}$ of (16) is given by replacing the above integrations by the adequate summations like in the previous section.

\subsection{Closed and wedged type of the sequential plans}

This is a modification of the unwedged type with a wedge-like boundary with the angle $\theta$, a little bit greater than $\pi / 4$, at the non-significance region, like in Fig. 3. The angle $\theta$ means that any sample path does not come back the continued region if the path enters once the non-significance region, and that $n_{t}-c+1$ pairs are minimumly needed to get the decision of non-significance.

The probabilities to accept $H_{i}$, for the triplet of $\left(p, c\right.$ and $\left.n_{t}\right)$ is quite the same as $\alpha_{i}(p)(i=1,2,3)$ in section 2.2 . 
On the other hand, the average sampling number $E\left(n \mid p, c, n_{t}\right)$ of favorable pairs is shown in the following way.

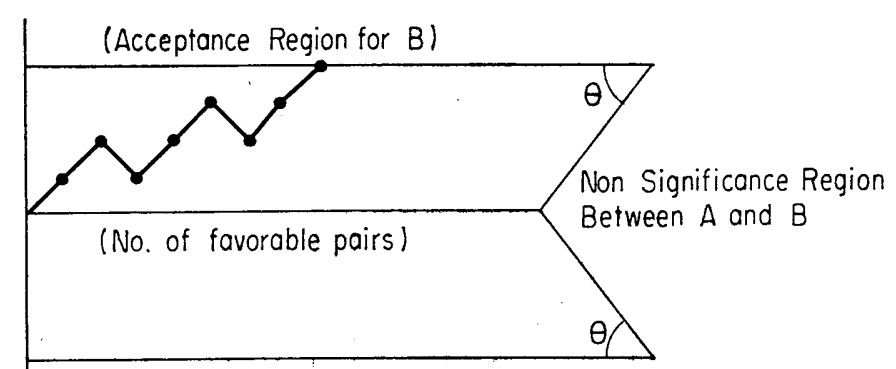

(Acceptance Region for A)

Fig. 3. Boundaries for a closed and wedged type of a two-sided sequential test.

$$
\begin{aligned}
E\left(n \mid p, c, n_{t}\right)= & {\left[n_{t}\left\{S_{h}(p)+S_{h}(q)\right\}-2 \sum_{j=0}^{h-1}\left\{S_{j}(p)+S_{j}(q)\right\}\right] \cdot E_{1} } \\
& +\sum_{j=3}^{2 d}\left(n_{t}-2 d+j\right)\left\{S_{h-d+1}(p) \cdot p^{j-3} \cdot q+S_{h-d+1}(q) \cdot p \cdot q^{j-3}\right\} \cdot E_{d} \\
& +(1-\delta)\left(n_{t}-c+2\right) \cdot S_{h-d+1}(p) \cdot E_{d+1},
\end{aligned}
$$

where $d=(c+\delta) / 2$ and $\delta=0$ for an even $c, \delta=1$ for an odd $c$.

From the viewpoint of minimum loss for an a priori distribution $f(p)$, the expected loss function can be obtained by the same formulation as in section 2.2. Whence, how to determine the optimum $c$ is game-theoretical.

\section{Numerical cases}

\subsection{Open type}

$\alpha_{1}^{*}(p)$ and $E(n \mid p, c)$ are given in Tab. I and II for each pair of $(c, p)$, where $c=5(1) 15$ and $p=0.1(0.1) 0.9$, and these curves on $p$ 's are drawn for $c=5(1) 15$ in Fig. I and II, respectively.

The values of $\overline{\mathrm{ELOSS}} / \mathrm{NG}$ are also available for $c=5(1) 15$ at Tab. III and these are shawn in Fig. III, for some cases of the a priori distributions of $p$, denoted by $L_{i}, S_{i}, R_{i}\left(i=1,2,3,1^{\prime}, 2^{\prime}\right)$ in Tab. 1 , in order to illustrate the behavior on $c$ 's, where $N=1,000$, and where the minimum $\overline{\text { E LOSS }} / \mathrm{NG}$ is denoted by (*) for each type of a priori distributions.

\subsection{Cases of closed types}

$\alpha_{1}\left(p ; c, n_{t}\right)$ 's are given in Tab. IV, for $n_{t}=10(1) 50, c=4(1) 24$, and $p=0.2(0.1) 0.8$, two curves of $\alpha_{1}(p)$ and $\alpha_{3}(p)$ are shown for $n_{t}=30(10) 50$ at Fig. IV for $c=4(4) 24$, and these illustrate the relations among $\alpha_{i}(p)$ 's $(i=1,2,3)$ due to $p$ 's.

The curve of $\alpha_{i}(p)(i=1,3)$ for the other value of $n_{t}$ may be also without any difficulty obtained by drawing the similar figure as Fig. IV based on Tab. IV.

Furthermore, the curve of $E\left(n \mid p, c, n_{t}\right)$ on $p$ 's (i. e., $\left.p=0.1(0.1) 0.9\right)$ is shown for 
Table 1 . The a priori distributions.

\begin{tabular}{|c|c|c|c|c|c|c|c|c|c|c|c|c|c|c|c|}
\hline \multirow{2}{*}{$\frac{\text { Type }}{p}$} & \multicolumn{3}{|c|}{$S_{1}$} & \multicolumn{3}{|c|}{$S_{2}$} & \multicolumn{3}{|c|}{$S_{3}$} & \multicolumn{3}{|c|}{$S_{1^{\prime}}$} & \multicolumn{3}{|c|}{$S_{2^{\prime}}$} \\
\hline & .7 & .8 & .9 & .6 & .7 & .8 & .4 & .5 & .6 & .1 & .2 & .3 & .2 & .3 & .4 \\
\hline$f(p)$ & .25 & .50 & .25 & .52 & .50 & .25 & .25 & .50 & .25 & .25 & .50 & .25 & .25 & .50 & .25 \\
\hline Type & \multicolumn{15}{|c|}{$S_{4}$} \\
\hline$p$ & .1 & .2 & .3 & .4 & .5 & .6 & $\begin{array}{ll}7 & .8\end{array}$ & 8.5 & & & & & & & \\
\hline$f(p)$ & $\frac{1}{9}$ & $\frac{1}{9}$ & $\begin{array}{l}1 \\
9 \\
\end{array}$ & $\frac{1}{9}$ & $\frac{1}{9}$ & $\frac{1}{9}$ & $\frac{1}{9} \quad \frac{1}{9}$ & $\frac{1}{9} \quad \frac{1}{9}$ & & & & & & & \\
\hline Type & \multicolumn{3}{|c|}{$\overline{R_{1}}$} & \multicolumn{3}{|c|}{$R_{2}$} & \multicolumn{3}{|c|}{$R_{3}$} & \multicolumn{3}{|c|}{$R_{1^{\prime}}$} & \multicolumn{3}{|c|}{$R_{2^{\prime}}$} \\
\hline$p$ & .7 & .8 & .9 & .6 & .7 & .8 & .4 & .5 & .6 & .1 & .2 & .3 & .2 & .3 & .4 \\
\hline$f(p)$ & .15 & .50 & .35 & .15 & .50 & .35 & .15 & .50 & .35 & .15 & .50 & .35 & .15 & .50 & .35 \\
\hline Type & \multicolumn{3}{|c|}{$L_{1}$} & \multicolumn{3}{|c|}{$L_{2}$} & \multicolumn{3}{|c|}{$L_{3}$} & \multicolumn{3}{|c|}{$L_{1^{\prime}}$} & \multicolumn{3}{|c|}{$L_{2^{\prime}}$} \\
\hline$p$ & .7 & .8 & .9 & .6 & .7 & .8 & .4 & .5 & .6 & .1 & .2 & .3 & .2 & .3 & .4 \\
\hline$f(p)$ & .35 & .50 & .15 & .35 & .50 & .15 & .35 & .50 & .15 & .35 & .50 & .15 & .35 & .50 & .15 \\
\hline
\end{tabular}

each pair $\left(n_{t}, c\right)$ of $n_{t}=10(5) 50$ and $c=4(2) 24$, by Fig. $V_{1}$ or $V_{2}$, by Fig. $V_{1}$ for the unwedged design or by Fig. $V_{2}$ for the wedged design.

The behaviors of $\overline{\mathrm{ELOSS}} / \mathrm{NG}$ on $c$ 's (i. e., $c=4(2) 24)$ are consequently explained for each of $n_{t}=10(5) 50$ by Fig. $\mathrm{VI}_{1}$ and $\mathrm{VI}_{2}$, by Fig. $\mathrm{VI}_{1}$ for the unwedged design and by Fig. $\mathrm{VI}_{2}$ for the wedged design for each type of a priori distributions in Tab. 1 .

\section{Properties of $\alpha_{i}(\boldsymbol{p}), \boldsymbol{E}(\boldsymbol{n})$ and $\overline{\mathrm{E} \text { LOSS }}$}

\subsection{Open type}

Firstly, the value of $\alpha_{1}^{*}(p)$ for a fixed $c=5(1) 15$ increases from 0 to 1 as $p$ increases from 0 to 1 , while it increases as $c$ increases from 5 to 15 when $p>0.5$, and decreases as $c$ increases when $p<0.5$.

Secondly, as to $E(n \mid p, c)$, the value of $E(n \mid p, c)$ for a fixed $p=0.1(0.1) 0.9$ increases as $c$ increases from 5 to 15 , and the curve on $p$ 's is like a Gaussian shape with the maximum height at $p=0.5$, for any $c=5(1) 15$.

Moreover, $E(n \mid p, c)=E(n \mid 1-p, c)$ for any $c$., and as for two a priori distributions whose probability distributions are mutually symmetric for $p=0.5$ (i. e., types $R_{i}$ and $L_{i^{\prime}}, S_{i}$ and $S_{i^{\prime}}, L_{i}$ and $R_{i^{\prime}}(i=1,2), R_{3}$ and $\left.L_{3}\right)$, the value of $\overline{\mathrm{ELOSS}} / \mathrm{NG}$ for a type is equal to that of the other, for a fixed $c$.

Let us consider a shape of the curve of $\overline{\mathrm{ELOSS}} / \mathrm{NG}$ which is drawn according to $c$ 's (i. e., $c=5(1) 15$ ), for each type of a priori distributions.

(1) Then the curve is concave for any type of a priori distributions.

(2) $\overline{\mathrm{ELOSS}} / \mathrm{NG}$ increases as the center of a priori distribution goes to 0.5 (, that is, $R_{1} \rightarrow S_{1} \rightarrow L_{1} \rightarrow R_{2} \rightarrow S_{2} \rightarrow L_{2} \rightarrow R_{3} \rightarrow S_{3}$ ) for a fixed $c$, and then the difference between 


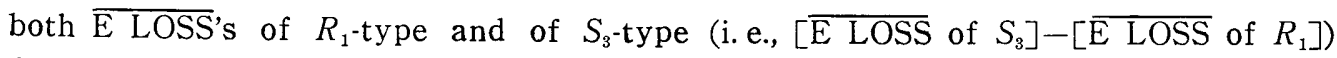
for the same $c$ comes to zero as $c$ increased.

(3) The optimum $c^{*}$ becomes large little by little for minimizing $\overline{\mathrm{E} \mathrm{LOSS}} / \mathrm{NG}$ as the center of a priori distribution goes to 0.5 (i. e., $R_{1} \rightarrow S_{1} \rightarrow \cdots \rightarrow R_{3} \rightarrow S_{3}$ ).

\subsection{Closed types}

Firstly, it is obvious that $\alpha_{3}(p)=\alpha_{1}(1-p)$ and $\alpha_{2}(p)=1-\left\{\alpha_{1}(p)+\alpha_{3}(p)\right\}$.

The followings become clear from Tab. IV and Fig. IV. (1) The value of $\alpha_{1}(p)$ increases from 0 to 1 as $p$ increases from 0.1 to 0.9 , for any pair $\left(n_{t}, c\right)$. (2) The value of $\alpha_{1}(p)$ decreases for any $\left(p, n_{t}\right)$ as $c$ increases from 4 to 24 , and moreover it shows a slight decrease when $n_{t}$ is not less than a certain value. (3) On the other hand, $\alpha_{1}(p)$ increases for any $(p, c)$ as $n_{t}$ increases from 10 to 50 , and further it shows a rapid increase when $c$ is larger than a certain value.

Secondly, as to the properties of $E\left(n \mid p, c, n_{t}\right)$, the following conclusions (1) (6) may be derived from Fig. $\mathrm{V}_{1}$ and $\mathrm{V}_{2}$.

(1) It is clear that $E\left(n \mid p, c, n_{t}\right)=E\left(n \mid 1-p, c, n_{t}\right)$ for any $\left(c, n_{t}\right)$.

(2) For any $n_{t}$ and $c$, the curve of $E\left(n \mid p, c, n_{t}\right.$ ) due to $p$ 's (i. e., $p=0.1(0.1) 0.9$ ) is like a Gaussian shape with the maximal height at $p=0.5$ in the unwedged design. However, in the wedged design, the curve $E\left(n \mid p, c, n_{t}\right)$ shows the locally minimum at $p=0.5$ when $c$ is not less than a certain integer (for example, when $c$ is not less than 16 for $n_{t}=49$ or 50 ).

(3) The function $E\left(n \mid p, c, n_{t}\right)$ of $c$ increases monotonously for any $n_{t}$ and the increase tends gradually as $n_{t}$ increases from 10 to 50 .

(4) The function $E\left(n \mid p, c, n_{t}\right)$ of $n_{t}$ also increases monotonously for any $c$ and it shows rapid increase as $c$ increases from 4 to 24 .

(5) The value of $E\left(n \mid p, c, n_{t}\right)$ of the wedged design is equal to or less than that of the unwedged for any $\left(p, n_{t}\right)$, except the case of $c=4$, and the difference between both values of $E\left(n \mid p, c, n_{t}\right)$ of these designs grows gradually large as a value $c$ increase. For example, the former is about 28 percent less than the latter for $p=0.5, n_{t}=50$, and $c=20$.

(6) When $p$ goes to 0.1 or 0.9 , the value of $E\left(n \mid p, c, n_{t}\right)$ of the wedged design also coincides well with that of the unwedged for any $\left(c, n_{t}\right)$.

In conclusion, the following results (1) (4) may be summerized with respect to

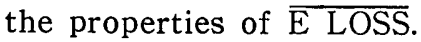

(1) When there are mutually symmetric a priori distributions for $p=0.5$ (i. e., types $R_{i}$ and $L_{i^{\prime}}, S_{i}$ and $S_{i^{\prime}}, L_{i}=R_{i^{\prime}}(i=1,2) R_{3}$ and $L_{3}$ ), a value of $\overline{\mathrm{E} L O S S} / \mathrm{NG}$ equals that of another distribution for any $\left(c, n_{t}\right)$, and also $\overline{\mathrm{E} L O S S} / \mathrm{NG}$ of type $S_{3}$ equals that of type $R_{3}$.

(2) The function $\overline{\mathrm{ELOSS}} / \mathrm{NG}$ of $c$ increases monotonously when $n_{t}$ is nearly less than 34 , and its increase becomes gradually flat as $n_{t}$ becomes fairly large. On the other hand, when $n_{t}$ is nearly equal to or larger than $34, \overline{\mathrm{E} \mathrm{LOSS}} / \mathrm{NG}$ shows concave with a minimum height at $c=5 \sim 7$. 
(3) The range of $\overline{\mathrm{ELOSS}} / \mathrm{NG}$, that is, $\left[\underset{\left(c, n_{t}\right)}{\mathrm{Eax}} \overline{\mathrm{ELOSS}} / \mathrm{NG}\right]-\left[\mathrm{Min}_{\left(c, n_{t}\right)} \overline{\mathrm{ELOSS}} / \mathrm{NG}\right]$ for $c=4(1) 24$, and $n_{t}=10(1) 50$ (where $2 c<n_{t}$ ) increases from 0.025 to 0.048 as a priori distribution changes from $R_{1}$ to $L_{2}$ through a route $R_{1} \rightarrow S_{1} \rightarrow L_{1} \rightarrow R_{2} \rightarrow S_{2} \rightarrow L_{2}$. This is summerized in Table 2 .

Table 2. Range of $\overline{\mathrm{ELOSS}} / \mathrm{NG}$, types $R_{i}, S_{i}, L_{i}(i=1,2)$.

\begin{tabular}{|c|c|c|c|c|c|c|}
\hline a priori distribution & $R_{1}$ & $S_{1}$ & $L_{1}$ & $R_{2}$ & $S_{2}$ & $L_{2}$ \\
\hline Max. $[\overline{\mathrm{ELOSS}} / \mathrm{NG}]$ & .028 & .033 & .039 & .051 & .053 & .055 \\
\hline Min. $[\overline{\text { E LOSS }} / \mathrm{NG}]$ & .003 & .003 & .004 & .005 & .006 & .007 \\
\hline Range & .025 & .030 & .035 & .046 & .047 & .048 \\
\hline
\end{tabular}

(Maximization and Minimization of $\overline{\mathrm{ELOSS}} / \mathrm{NG}$ are considered under the conditions $4 \leqq c \leqq 24,10 \leqq n \leqq 50$, and $2 c \leqq n_{t}$.)

The range of $\overline{\mathrm{ELOSS}} / \mathrm{NG}$ of type $S_{4}$ is larger than that of types $R_{3}, S_{3}$, and $L_{3}$ as follows.

Table 3. Range of $\overline{\mathrm{E} \mathrm{LOSS}} / \mathrm{NG}$, types $R_{3}, S_{3}, L_{3}$, and $S_{4}$.

\begin{tabular}{l|c|c}
\hline$a$ priori distribution & $R_{3}, S_{3}, L_{3}$ & $S_{4}$ \\
\hline Max. [E LOSS/NG] & .025 & .082 \\
\hline Min. [E LOSS/NG] & .007 & .005 \\
\hline Range & .018 & .077 \\
\hline
\end{tabular}

(4) For any type of a priori distributions in Tab. 1, the value of $\overline{\mathrm{E} \mathrm{LOSS}} / \mathrm{NG}$ of the wedged design almost coincides with that of the unwedged design for any pair $\left(c, n_{t}\right)$.

Therefore it is worthless for us to consider some differences between a wedged and an unwedged designs in view of minimizing ethycal $\overline{\mathrm{E} \text { LOSS }} / \mathrm{NG}$.

(5) When $n_{t}$ may be at least 50 from our physical aspects, the optimum designs, giving the minimum $\overline{\mathrm{ELOSS}} / \mathrm{NG}$, are summerized in Tab. 4, for a priori distributions and wedged and unwedged designs.

\section{Examples}

\subsection{Open type}

Example 1. When $p$ is not less than 0.6 , determine a value $c$ by which $B$-acceptance region may be decided in order to select treatment $B$ as the better with probability 0.95 at least. From Tab. I or Fig. I, the value $c$ must be at least equal to 8 .

Example 2. When $c=10$ in Ex. 1, find out an average sampling number of favorable pair of patients in case of open type. It is 30 pairs at the most from Tab. II or Fig. II.

Example 3. When an a priori distribution $f(p)$ is either of three types $L_{2}, S_{2}$, 
Table 4. Optimum Designs.

\begin{tabular}{|c|c|c|c|c|c|c|}
\hline \multirow{2}{*}{$\begin{array}{c}\text { a priori } \\
\text { distribution }\end{array}$} & \multicolumn{3}{|c|}{ Unwedged Design } & \multicolumn{3}{|c|}{ Wedged Design } \\
\hline & $n_{t}$ & $c$ & Min. [E LOSS/NG] & $n_{t}$ & $c$ & Min. [E LOSS/NG] \\
\hline \multirow{2}{*}{$R_{1}$} & 31 & 5 & \multirow{2}{*}{0.003} & 31 & 5 & \multirow{2}{*}{0.003} \\
\hline & 40 & 6 & & 40 & 6 & \\
\hline \multirow{2}{*}{$S_{1}$} & 41 & 5 & \multirow{2}{*}{0.003} & 43 & 5 & \multirow{2}{*}{0.003} \\
\hline & 48 & 6 & & 50 & 6 & \\
\hline \multirow{3}{*}{$L_{1}$} & 31 & 5 & \multirow{3}{*}{0.004} & 31 & 5 & \multirow{3}{*}{0.004} \\
\hline & 36 & 6 & & 36 & 6 & \\
\hline & 43 & 7 & & 43 & 7 & \\
\hline$R_{2}$ & 50 & 6 & 0.005 & 50 & 6 & 0.005 \\
\hline \multirow{3}{*}{$S_{2}$} & \multirow{3}{*}{50} & \multirow{3}{*}{6} & \multirow{3}{*}{0.006} & 43 & 5 & \multirow{3}{*}{0.007} \\
\hline & & & & 42 & 6 & \\
\hline & & & & 47 & 7 & \\
\hline \multirow{3}{*}{$L_{2}$} & 45 & 5 & \multirow{3}{*}{0.008} & 47 & 5 & \multirow{3}{*}{0.008} \\
\hline & 44 & 6 & & 44 & 6 & \\
\hline & 47 & 7 & & 47 & 7 & \\
\hline \multirow{3}{*}{$R_{3}, S_{3}, L_{3}$} & 47 & 5 & \multirow{3}{*}{0.007} & 47 & 5 & \multirow{3}{*}{0.007} \\
\hline & 44 & 6 & & 46 & 6 & \\
\hline & 49 & 7 & & 49 & 7 & \\
\hline$S_{4}$ & 48 & 6 & 0.005 & 50 & 6 & 0.005 \\
\hline
\end{tabular}

or $R_{2}$, and when $c=8$ in Ex. 1 , it follows from Tab. III that the $\overline{\mathrm{E} \mathrm{LOSS}} / \mathrm{NG}$ is at least about 77.8 per cent more than the minimum $\overline{\mathrm{ELOSS}} / \mathrm{NG}$, since the $\overline{\mathrm{ELOSS}} / \mathrm{NG}$ is 0.00096 for $c=8$ and then the minimum $=0.00054$ (, where $c=12$ or 13 gives the minimum) in the case of type $R_{2}$, and the $\overline{\mathrm{ELOSS}} / \mathrm{NG}$ is 0.00132 for $c=8$ and then the minimum $=0.00057$ in the case of type $S_{2}$, and moreover the $\overline{\mathrm{ELOSS}} / \mathrm{NG}$ is 0.00169 for $c=8$ and then the minimum $=0.00059$ in the case of type $L_{2}$.

\subsection{Closed types}

Example 4. Assume that the effective probability $p_{A}$ of standard treatment $A$ is known to be 0.60 , and $p_{B}$ of test treatment $B$ estimated to be either of three values $0.86,0.78$, and 0.69 . Find out the probabilities which treatment $A$ and $B$ may be selected as the better by a closed type where $n_{t}=40$ and $c=10$. The answer is given from Tab. IV or Fig. IV, that is, $p \fallingdotseq 0.80,0.70$ or 0.60 for $p_{B}=0.86,0.78$ or 0.69 , respectively. Therefore, the probability for selecting $B$ i. e., $\alpha_{1}(p)=0.9979$ or 0.9093 
or 0.5107 , respectively. Also, the probability for selecting $A$, i. e. $\alpha_{3}(p)$, is $0,0.0002$ or 0.0089 , respectively.

Example 5. Find out the number of the average sampling number of favorable pair of patients for each value of $p_{B}$ 's assumed in Ex. 4 in cases of the unwedged and the wedged designs.

Fig. $V_{1}$ and $V_{2}$ give the following answer (Tab. 5).

Table 5. $E\left(n \mid p, c, n_{t}\right)$ for $n_{t}=40, c=10$.

\begin{tabular}{c|c|c|c}
\hline$p_{B}$ & $p$ & Unwedged Design & Wedged Design \\
\hline 0.86 & 0.80 & 17 & 17 \\
\hline 0.78 & 0.70 & 24 & 24 \\
\hline 0.60 & 0.60 & 33 & 31 \\
\hline
\end{tabular}

From Tab. 5, the ASN of the wedged design becomes less than that of the unwedged when $p=0.60$, that is, $p$ is about 0.5 nearer than 0.70 or 0.80 .

Example 6. Assume that an a priori distribution $f(p)$ is type $S_{2}$. Find out the $\overline{\mathrm{ELOSS}} / \mathrm{NG}$ for $c=10, n_{t}=42$ and the minimum $\overline{\mathrm{E} \mathrm{LOSS}} / \mathrm{NG}$ for $n_{t}=42$, in each case of both designs.

These values required above are nearly 0.014 and 0.007 in both cases, respectively, from Fig. $\mathrm{VI}_{1}$ and $\mathrm{VI}_{2}$, and therefore the former has about twice of the latter, and moreover the optimum value $c^{*}$ for $n_{t}=42$ is 6 , that is, less than $c=10$.

If we determine $B$-acceptance region as $c=4$, the $\overline{\mathrm{E} \mathrm{LOSS}} / \mathrm{NG}$ for $c=4$, is about 28.6 per cent more than the minimum $\overline{\mathrm{E} \mathrm{LOSS}} / \mathrm{NG}$ for the optimal $c^{*}=6$, where $n_{t}=42$ in the same manner mentioned above. 


\section{Numerical tables and figures}

Table I. $\alpha_{1}^{*}(p)$ of Open Type.

\begin{tabular}{|c|c|c|c|c|c|c|c|c|c|}
\hline$p$ & 0.9 & 0.8 & 0.7 & 0.6 & 0.5 & 0.4 & 0.3 & 0.2 & 0.1 \\
\hline 5 & 0.99998 & 0.99902 & 0.98575 & 0.88364 & 0.50000 & 0.11636 & 0.01425 & 0.00098 & 0.00002 \\
\hline 6 & 1.00000 & 0.99976 & 0.99384 & 0.91929 & 0.50000 & 0.08071 & 0.00616 & 0.00024 & 0.00000 \\
\hline 7 & 1. 00000 & 0.99994 & 0.99735 & 0.94471 & 0.50000 & 0.05529 & 0.00265 & 0.00006 & 0.00000 \\
\hline 8 & 1.00000 & 0.99998 & 0.99886 & 0.96245 & 0.50000 & 0.03755 & 0.00114 & 0.00002 & 0.00000 \\
\hline 9 & 1.00000 & 1.00000 & 0.99951 & 0.97465 & 0.50000 & 0.02535 & 0.00049 & 0.00000 & 0.00000 \\
\hline 10 & 1. 00000 & 1.00000 & 0.99979 & 0.98295 & 0.50000 & 0.01705 & 0.00021 & 0.00000 & 0.00000 \\
\hline 11 & 1. 00000 & 1. 00000 & 0.99991 & 0.98857 & 0.50000 & 0.01143 & 0.00009 & 0.00000 & 0.00000 \\
\hline 12 & 1.00000 & 1.00000 & 0.99996 & 0.99235 & 0.50000 & 0.00765 & 0.00004 & 0.00000 & 0.00000 \\
\hline 13 & 1.00000 & 1.00000 & 0.99998 & 0.99489 & 0.50000 & 0.00511 & 0.00002 & 0.00000 & 0.00000 \\
\hline 14 & 1. 00000 & 1. 00000 & 0.99999 & 0.99659 & 0.50000 & 0.00341 & 0.00001 & 0.00000 & 0.00000 \\
\hline 15 & 1. 00000 & 1. 00000 & 1.00000 & 0.99772 & 0.50000 & 0.00228 & 0.00000 & 0.00000 & 0.00000 \\
\hline
\end{tabular}

Table II. The Average Sampling Favorable Pair-Numbers of Open Type.

\begin{tabular}{|c|c|c|c|c|c|c|c|c|c|}
\hline$c \quad p$ & 0.1 & 0.2 & 0.3 & 0.4 & 0.5 & 0.6 & 0.7 & 0.8 & 0.9 \\
\hline 5 & 5. 62489 & 6.65854 & 8.57185 & 12.09091 & 15. 00000 & 12.09091 & 8. 57185 & 6.65854 & 5. 62489 \\
\hline 6 & 6.74999 & 7. 99756 & 10.40763 & 15.57881 & 21. 00000 & 15.57881 & 10.40763 & 7. 99756 & 6. 74999 \\
\hline 7 & 7. 87500 & 9. 33262 & 12.20365 & 19.06479 & 28. 00000 & 19. 06479 & 12. 20365 & 9. 33262 & 7. 87500 \\
\hline 8 & 9. 00000 & 10. 66646 & 13.97726 & 22.49786 & 36.00000 & 22. 49786 & 13. 97726 & 10.66646 & 9.00000 \\
\hline 9 & 10.12500 & 11. 99994 & 15.73903 & 25. 85912 & 45. 00000 & 25.85912 & 15. 73903 & 11.99994 & 10.12500 \\
\hline 10 & 11.25000 & 13. 33332 & 17.49477 & 29.14769 & 55.00000 & 29. 14769 & 17. 49477 & 13. 33332 & 11. 25000 \\
\hline 11 & 12.37500 & 14.66666 & 19.24753 & 32.37140 & 66.00000 & 32. 37140 & 19. 24753 & 14.66666 & 12.37500 \\
\hline 12 & 13.50000 & 16.00000 & 20.99884 & 35.54108 & 78.00000 & 35.54108 & 20.99884 & 16.00000 & 13.50000 \\
\hline 13 & 14. 62500 & 17.33333 & 22.74945 & 38.66771 & 91.00000 & 38.66771 & 22.74945 & 17.33333 & 14. 62500 \\
\hline 14 & 15.75000 & 18. 66666 & 24.49974 & 41.76102 & 105.00000 & 41.76102 & 24. 49974 & 18. 66666 & 15. 75000 \\
\hline 15 & 16.87498 & 19. 99998 & 26. 24988 & 44.82910 & 120.00000 & 44.82910 & 26. 24988 & 19. 99998 & 16. 87498 \\
\hline
\end{tabular}

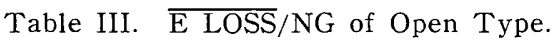

\begin{tabular}{|c|c|c|c|c|c|c|c|c|}
\hline$c$ Type & $R_{1}, L_{1}^{\prime}$ & $S_{1}, S_{1}{ }^{\prime}$ & $L_{1}, R_{1}{ }^{\prime}$ & $R_{2}, L_{2}^{\prime}$ & $S_{2}, S_{2}^{\prime}$ & $L_{2}, R_{2}^{\prime}$ & $R_{3}, S_{3}, L_{3}$ & $S_{4}$ \\
\hline 5 & 0.00078 & 0.00106 & 0.00134 & 0.00345 & 0.00457 & 0.00569 & 0.00587 & 0.00341 \\
\hline 6 & 0.00046 & 0.00058 & 0.00070 & 0.00206 & 0.00285 & 0.00364 & 0.00410 & 0.00225 \\
\hline 7 & 0.00038 & 0.00042 & 0.00047 & 0.00134 & 0.00188 & 0.00242 & 0.00285 & 0.00156 \\
\hline 8 & $0.00036^{(*)}$ & $0.00037^{(*)}$ & $0.00039(*)$ & 0.00096 & 0.00132 & 0.00169 & 0.00198 & 0.00113 \\
\hline 9 & 0.00038 & 0.00038 & $0.00039(*)$ & 0.00075 & 0.00099 & 0.00124 & 0.00139 & 0.00087 \\
\hline 10 & 0.00042 & 0.00041 & 0.00040 & 0.00063 & 0.00079 & 0.00095 & 0.00099 & 0.00071 \\
\hline 11 & 0.00045 & 0.00044 & 0.00044 & 0.00057 & 0.00068 & 0.00078 & 0.00073 & 0.00062 \\
\hline 12 & 0.00049 & 0.00048 & 0.00047 & $0.00054^{(*)}$ & 0.00061 & 0.00067 & 0.00056 & 0.00056 \\
\hline 13 & 0.00053 & 0.00052 & 0.00051 & $0.00054^{(*)}$ & 0.00058 & 0.00062 & 0.00045 & $0.00054^{(*)}$ \\
\hline 14 & 0.00057 & 0.00056 & 0.00055 & 0.00055 & $0.00057(*)$ & $0.00059(*)$ & 0.00038 & $0.00054^{(*)}$ \\
\hline 15 & 0.00061 & 0.00060 & 0.00058 & 0.00057 & 0.00058 & $0.00059(*)$ & $0.00034^{(*)}$ & $0.00054^{(*)}$ \\
\hline
\end{tabular}


Table IV. $\alpha_{1}\left(0.2 ; c, n_{t}\right)$ of Closed Type (continued), $c=4(1) 24, n_{t}=10(1) 50$.

\begin{tabular}{|c|c|c|c|c|c|c|c|c|c|}
\hline$n_{t}$ & $\begin{array}{c}4 \\
(5)\end{array}$ & $\begin{array}{c}6 \\
(7)\end{array}$ & $\begin{array}{c}8 \sim 24 \\
(9)\end{array}$ & & $\begin{array}{c}4 \\
(5)\end{array}$ & $\begin{array}{c}6 \\
(7)\end{array}$ & $\begin{array}{c}8 \\
(9)\end{array}$ & $\begin{array}{c}10 \\
(11)\end{array}$ & $\begin{array}{c}12 \sim 24 \\
(13)\end{array}$ \\
\hline 10 & 0.0035 & 0.0002 & 0.0000 & 10 & 0.0235 & 0.0025 & 0.0003 & 0.0000 & 0.0000 \\
\hline 11 & 0.0008 & 0.0000 & 0.0000 & 11 & 0.0088 & 0.0009 & 0.0001 & 0.0000 & 0.0000 \\
\hline 12 & 0.0037 & 0.0002 & 0.0000 & 12 & 0.0261 & 0.0033 & 0.0003 & 0.0000 & 0.0000 \\
\hline 13 & 0.0009 & 0.0000 & 0.0000 & 13 & 0.0101 & 0.0012 & 0.0001 & 0.0000 & 0.0000 \\
\hline 14 & 0.0038 & 0.0002 & 0.0000 & 14 & 0.0279 & 0.0039 & 0.0004 & 0.0000 & 0.0000 \\
\hline 15 & 0.0009 & 0.0001 & 0.0000 & 15 & 0.0111 & 0.0015 & 0.0002 & 0.0000 & 0.0000 \\
\hline 16 & 0.0038 & 0.0002 & 0.0000 & 16 & 0.0293 & 0.0044 & 0.0005 & 0.0001 & 0.0000 \\
\hline 17 & 0.0009 & 0.0001 & 0.0000 & 17 & 0.0119 & 0.0017 & 0.0002 & 0.0000 & 0.0000 \\
\hline 18 & 0.0039 & 0.0002 & 0.0000 & 18 & 0.0302 & 0.0047 & 0.0006 & 0.0001 & 0.0000 \\
\hline 19 & 0.0010 & 0.0001 & 0.0000 & 19 & 0.0124 & 0.0019 & 0.0002 & 0.0000 & 0.0000 \\
\hline 20 & 0.0039 & 0.0002 & 0.0000 & 20 & 0.0309 & 0.0050 & 0.0007 & 0.0001 & 0.0000 \\
\hline 21 & 0.0010 & 0.0001 & 0.0000 & 21 & 0.0129 & 0.0020 & 0.0003 & 0.0000 & 0.0000 \\
\hline 22 & 0.0039 & 0.0002 & 0.0000 & 22 & 0.0314 & 0.0053 & 0.0008 & 0.0001 & 0.0000 \\
\hline 23 & 0.0010 & 0.0001 & 0.0000 & 23 & 0.0132 & 0.0022 & 0.0003 & 0.0000 & 0.0000 \\
\hline 24 & 0.0039 & 0.0002 & 0.0000 & 24 & 0.0317 & 0.0055 & 0.0009 & 0.0001 & 0.0000 \\
\hline 25 & 0.0010 & 0.0001 & 0.0000 & 25 & 0.0315 & 0.0023 & 0.0003 & 0.0000 & 0.0000 \\
\hline 26 & 0.0039 & 0.0002 & 0.0000 & 26 & 0.0320 & 0.0056 & 0.0009 & 0.0001 & 0.0000 \\
\hline 27 & 0.0010 & 0.0001 & 0.0000 & 27 & 0.0136 & 0.0023 & 0.0004 & 0.0001 & 0.0000 \\
\hline 28 & 0.0039 & 0.0002 & 0.0000 & 28 & 0.0322 & 0.0057 & 0.0010 & 0.0002 & 0.0000 \\
\hline 29 & 0.0010 & 0.0001 & 0.0000 & 29 & 0.0138 & 0.0024 & 0.0004 & 0.0001 & 0.0000 \\
\hline 30 & 0.0039 & 0.0002 & 0.0000 & 30 & 0.0323 & 0.0058 & 0.0010 & 0.0002 & 0.0000 \\
\hline 31 & 0.0010 & 0.0001 & 0.0000 & 31 & 0.0139 & 0.0024 & 0.0004 & 0.0001 & 0.0000 \\
\hline 32 & 0.0039 & 0.0002 & 0.0000 & 32 & 0.0324 & 0.0059 & 0.0010 & 0.0002 & 0.0000 \\
\hline 33 & 0.0010 & 0.0001 & 0.0000 & 33 & 0.0140 & 0.0025 & 0.0004 & 0.0001 & 0.0000 \\
\hline 34 & 0.0039 & 0.0002 & 0.0000 & 34 & 0.0325 & 0.0060 & 0.0010 & 0.0002 & 0.0000 \\
\hline 35 & 0.0010 & 0.0001 & 0.0000 & 35 & 0.0141 & 0.0025 & 0.0004 & 0.0001 & 0.0000 \\
\hline 36 & 0.0039 & 0.0002 & 0.0000 & 36 & 0.0325 & 0.0060 & 0.0011 & 0.0002 & 0.0000 \\
\hline 37 & 0.0010 & 0.0001 & 0.0000 & 37 & 0.0141 & 0.0025 & 0.0004 & 0.0001 & 0.0000 \\
\hline 38 & 0.0039 & 0.0002 & 0.0000 & 38 & 0.0326 & 0.0060 & 0.0011 & 0.0002 & 0.0000 \\
\hline 39 & 0.0010 & 0.0001 & 0.0000 & 39 & 0.0141 & 0.0026 & 0.0005 & 0.0001 & 0.0000 \\
\hline 40 & 0.0039 & 0.0002 & 0.0000 & 40 & 0.0326 & 0.0061 & 0.0011 & 0.0002 & 0.0000 \\
\hline 41 & 0.0010 & 0.0001 & 0.0000 & 41 & 0.0142 & 0.0026 & 0.0005 & 0.0001 & 0.0000 \\
\hline 42 & 0.0039 & 0.0002 & 0.0000 & 42 & 0.0326 & 0.0061 & 0.0011 & 0.0002 & 0.0000 \\
\hline 43 & 0.0010 & 0.0001 & 0.0000 & 43 & 0.0142 & 0.0026 & 0.0005 & 0.0001 & 0.0000 \\
\hline 44 & 0.0039 & 0.0002 & 0.0000 & 44 & 0.0326 & 0.0061 & 0.0011 & 0.0002 & 0.0000 \\
\hline 45 & 0.0010 & 0.0001 & 0.0000 & 45 & 0.0142 & 0.0026 & 0.0005 & 0.0001 & 0.0000 \\
\hline 46 & 0.0039 & 0.0002 & 0.0000 & 46 & 0.0326 & 0.0061 & 0.0011 & 0.0002 & 0.0000 \\
\hline 47 & 0.0010 & 0.0001 & 0.0000 & 47 & 0.0142 & 0.0026 & 0.0005 & 0.0001 & 0.0000 \\
\hline 48 & 0.0039 & 0.0002 & 0.0000 & 48 & 0.0326 & 0.0061 & 0.0011 & 0.0002 & 0.0000 \\
\hline 49 & 0.0010 & 0.0001 & 0.0000 & 49 & 0.0142 & 0.0026 & 0.0005 & 0.0001 & 0.0000 \\
\hline 50 & 0.0039 & 0.0002 & 0.0000 & 50 & 0.0326 & 0.0061 & 0.0011 & 0.0002 & 0.0000 \\
\hline
\end{tabular}

Table IV. $\quad \alpha_{1}\left(0.3 ; c, n_{t}\right)$ of Closed Type (continued), $c=4(1) 24, n_{t}=10(1) 50$. 
Table IV. $\alpha_{1}\left(0.4 ; c, n_{t}\right)$ of Closed Type (continued), $c=4(1) 24, n_{t}=10(1) 50$.

\begin{tabular}{|c|c|c|c|c|c|c|c|c|c|}
\hline & $\begin{array}{c}4 \\
(5)\end{array}$ & $\begin{array}{c}6 \\
(7)\end{array}$ & $\begin{array}{c}8 \\
(9)\end{array}$ & $\begin{array}{c}10 \\
(11)\end{array}$ & $\begin{array}{c}12 \\
(13)\end{array}$ & $\begin{array}{c}14 \\
(15)\end{array}$ & $\begin{array}{c}16 \\
(17)\end{array}$ & $\begin{array}{c}18 \\
(19)\end{array}$ & $\begin{array}{c}20 \sim 24 \\
(21)\end{array}$ \\
\hline 10 & 0.0878 & 0.0164 & 0.0036 & 0.0007 & 0.0002 & 0.0000 & 0.0000 & 0.0000 & 0.0000 \\
\hline 11 & 0.0449 & 0.0077 & 0.0016 & 0.0003 & 0.0001 & 0.0000 & 0.0000 & 0.0000 & 0.0000 \\
\hline 12 & 0.1017 & 0.0226 & 0.0036 & 0.0007 & 0.0002 & 0.0000 & 0.0000 & 0.0000 & 0.0000 \\
\hline 13 & 0.0543 & 0.0112 & 0.0016 & 0.0003 & 0.0001 & 0.0000 & 0.0000 & 0.0000 & 0.0000 \\
\hline 14 & 0.1132 & 0.0284 & 0.0055 & 0.0007 & 0.0002 & 0.0000 & 0.0000 & 0.0000 & 0.0000 \\
\hline 15 & 0.0624 & 0.0146 & 0.0026 & 0.0003 & 0.0001 & 0.0000 & 0.0000 & 0.0000 & 0.0000 \\
\hline 16 & 0.1225 & 0.0338 & 0.0074 & 0.0013 & 0.0002 & 0.0000 & 0.0000 & 0.0000 & 0.0000 \\
\hline 17 & 0.0695 & 0.0180 & 0.0037 & 0.0006 & 0.0001 & 0.0000 & 0.0000 & 0.0000 & .0000 \\
\hline 18 & 0.1302 & 0.0386 & 0.0094 & 0.0018 & 0.0003 & 0.0000 & 0.0000 & 0.0000 & 0.0000 \\
\hline 19 & 0.0757 & 0.0211 & 0.0049 & 0.0009 & 0.0001 & 0.0000 & 0.0000 & 0.0000 & 0.0000 \\
\hline 20 & 0.1365 & 0.0430 & 0.0114 & 0.0025 & 0.0004 & 0.0001 & 0.0000 & 0.0000 & .0000 \\
\hline 21 & 0.0810 & 0.0240 & 0.0060 & 0.0013 & 0.0002 & 0.0000 & 0.0000 & 0.0000 & 0.0000 \\
\hline 22 & 0.1416 & 0.0469 & 0.0132 & 0.0032 & 0.0006 & 0.0001 & 0.0000 & 0.0000 & 0.0000 \\
\hline 23 & 0.0857 & 0.0267 & 0.0072 & 0.0016 & 0.0003 & 0.0000 & 0.0000 & 0.0000 & 0.0000 \\
\hline 24 & 0.1458 & 0.0504 & 0.0150 & 0.0039 & 0.0008 & 0.0002 & 0.0000 & 0.0000 & 0.0000 \\
\hline 25 & 0.0897 & 0.0292 & 0.0083 & 0.0021 & 0.0004 & 0.0001 & 0.0000 & 0.0000 & 0.0000 \\
\hline 26 & 0.1493 & 0.0536 & 0.0167 & 0.0046 & 0.0011 & 0.0002 & 0.0000 & 0.0000 & 0.0000 \\
\hline 27 & 0.0932 & 0.0314 & 0.0094 & 0.0025 & 0.0006 & 0.0001 & 0.0000 & 0.0000 & 0.0000 \\
\hline 28 & 0.1521 & 0.0564 & 0.0182 & 0.0052 & 0.0013 & 0.0003 & 0.0001 & 0.0000 & 0.0000 \\
\hline 29 & 0.0963 & 0.0335 & 0.0104 & 0.0029 & 0.0007 & 0.0001 & 0.0000 & 0.0000 & 0.0000 \\
\hline 30 & 0.1544 & 0.0589 & 0.0197 & 0.0059 & 0.0016 & 0.0004 & 0.0001 & 0.0000 & 0.0000 \\
\hline 31 & 0.0989 & 0.0354 & 0.0114 & 0.0033 & 0.0009 & 0.0002 & 0.0000 & 0.0000 & 0.0000 \\
\hline 32 & 0.1563 & 0.0612 & 0.0210 & 0.0066 & 0.0018 & 0.0005 & 0.0001 & 0.0000 & 0.0000 \\
\hline 33 & 0.1012 & 0.0372 & 0.0123 & 0.0 & 0.0010 & 0.0002 & 0.0001 & 0.0000 & 0.0000 \\
\hline 34 & 0.1579 & 0.0632 & 0.0223 & 0.0072 & 0.0021 & 0.0006 & 0.0001 & 0.0000 & 0.0000 \\
\hline 35 & 0.1032 & 0.0387 & 0.0132 & 0.0041 & 0.0012 & 0.0003 & 0.0001 & 0.0000 & 0.0000 \\
\hline 36 & 0.1592 & 0.0651 & 0.0234 & 0.0078 & 0.0024 & 0.0006 & 0.0002 & 0.0000 & 0.0000 \\
\hline 37 & 0.1050 & 0.0402 & 0.0140 & 0.0045 & 0.0013 & 0.0004 & 0.0001 & 0.0000 & 0.0000 \\
\hline 38 & 0.1602 & 0.0667 & 0.0245 & 0.0083 & 0.0026 & 0.0007 & 0.0002 & 0.0000 & 0.0000 \\
\hline 39 & 0.1065 & 0.0415 & 0.0148 & 0.0049 & 0.0015 & 0.0004 & 0.0001 & 0.0000 & 0.0000 \\
\hline 40 & 0.1611 & 0.0682 & 0.0255 & 0.0089 & 0.0028 & 0.0008 & 0.0002 & 0.0001 & 0.0000 \\
\hline 41 & 0.1078 & 0.0427 & 0.0155 & 0.0053 & 0.0016 & 0.0005 & 0.0001 & 0.0000 & 0.0000 \\
\hline 42 & 0.1618 & 0.0695 & 0.0264 & 0.0094 & 0.0031 & 0.0009 & 0.0003 & 0.0001 & 0.0000 \\
\hline 43 & 0.1089 & 0.0438 & 0.0162 & 0.0056 & 0.0018 & 0.0005 & 0.0001 & 0.0000 & 0.0000 \\
\hline 44 & 0.1623 & 0.0706 & 0.0273 & 0.0098 & 0.0033 & 0.0010 & 0.0003 & 0.0001 & 0.0000 \\
\hline 45 & 0.1099 & 0.0448 & 0.0168 & 0.0059 & 0.0020 & 0.0006 & 0.0002 & 0.0000 & 0.0000 \\
\hline 46 & 0.1628 & 0.0717 & 0.0281 & 0.0103 & 0.0035 & 0.0011 & 0.0003 & 0.0001 & 0.0000 \\
\hline 47 & 0.1107 & 0.0457 & 0.0174 & 0.0062 & 0.0021 & 0.0007 & 0.0002 & 0.0001 & 0.0000 \\
\hline 48 & 0.1632 & 0.0726 & 0.0288 & 0.0107 & 0.0038 & 0.0012 & 0.0004 & 0.0001 & 0.0000 \\
\hline 49 & 0.1115 & 0.0466 & 0.0179 & 0.0065 & 0.0022 & 0.0007 & 0.0002 & 0.0001 & 0.0000 \\
\hline 50 & 0.1635 & 0.0735 & 0.0295 & 0.0111 & 0.0040 & 0.0013 & 0.0004 & 0.0001 & 0.0000 \\
\hline
\end{tabular}


Table IV. $\alpha_{1}\left(0.5 ; c, n_{t}\right)$ of Closed Type (continued), $c=4(1) 24, n_{t}=10(1) 50$.

\begin{tabular}{|c|c|c|c|c|c|c|c|c|c|c|c|}
\hline & $\begin{array}{c}4 \\
(5)\end{array}$ & $\begin{array}{c}6 \\
(7)\end{array}$ & $\begin{array}{c}8 \\
(9)\end{array}$ & $\begin{array}{c}10 \\
\text { (11) }\end{array}$ & $\begin{array}{c}12 \\
(13)\end{array}$ & $\begin{array}{c}14 \\
(15)\end{array}$ & $\begin{array}{c}16 \\
(17)\end{array}$ & $\begin{array}{c}18 \\
(19)\end{array}$ & $\begin{array}{c}20 \\
(21)\end{array}$ & $\begin{array}{c}22 \\
(23)\end{array}$ & 24 \\
\hline 10 & 0.2266 & 0.0654 & 0.0225 & 0.0074 & 0.0023 & 0.0007 & 0.0002 & 0.0001 & 0.0000 & 0.0000 & 0.0000 \\
\hline 11 & 0.1460 & 0.0386 & 0.0129 & 0.0042 & 0.0013 & 0.0004 & 0.0001 & 0.0000 & 0.0000 & 0.0000 & \\
\hline 12 & 0.2666 & 0.0923 & 0.0225 & 0.0074 & 0.0023 & 0.0007 & 0.0002 & 0.0001 & 0.0000 & 0.0000 & 0000 \\
\hline 13 & 0.1796 & 0.0574 & 0.0129 & 0.0042 & 0.0013 & 0.0004 & 0.0001 & 0.0000 & 0.0000 & 0.0000 & \\
\hline 14 & 0.3008 & 0.1185 & 0.0352 & 0.0074 & 0.0023 & 0.0007 & 0.0002 & 0.0001 & 0.0000 & 0.0000 & 0.0000 \\
\hline 15 & 0.2101 & 0.0768 & 0.0213 & 0.0042 & 0.0013 & 0.0004 & 0.0001 & 0.0000 & 0.0000 & 0.0000 & \\
\hline 16 & 0.3300 & 0.1435 & 0.0490 & 0.0127 & 0.0023 & 0.0007 & 0.0002 & 0.0001 & 0.0000 & 0.0000 & 0.0000 \\
\hline 17 & 0.2377 & 0.0963 & 0.0309 & 0.0075 & 0.0013 & 0.0004 & 0.0001 & 0.0000 & 0.0000 & 0.0000 & \\
\hline 18 & 0.3549 & 0.1671 & 0.0636 & 0.0192 & 0.0044 & 0.0007 & 0.0002 & 0.0001 & 0.0000 & 0.0000 & 0.0000 \\
\hline 19 & 0.2628 & 0.1153 & 0.0414 & 0.0118 & 0.0026 & 0.0004 & 0.0001 & 0.0000 & 0.0000 & 0.0000 & \\
\hline 20 & 0.3761 & 0.1892 & 0.0784 & 0.0266 & 0.0072 & 0.0015 & 0.0002 & 0.0001 & 0.0000 & 0.0000 & 0.0000 \\
\hline 21 & 0.2854 & 0.1338 & 0.0525 & 0.0169 & 0.0043 & 0.0009 & 0.0001 & 0.0000 & 0.0000 & 0.0000 & \\
\hline 22 & 0.3945 & 0.2100 & 0.0931 & 0.0347 & 0.0106 & 0.0026 & 0.0005 & 0.0001 & 0.0000 & 0.0000 & 0.0000 \\
\hline 23 & 0.3059 & 0.1516 & 0.0639 & 0.0227 & 0.0066 & 0.0015 & 0.0003 & 0.0000 & 0.0000 & 0.0000 & \\
\hline 24 & 0.4097 & 0.2294 & 0.1078 & 0.0433 & 0.0146 & 0.0041 & 0.0009 & 0.0002 & 0.0000 & 0.0000 & 0.0000 \\
\hline 25 & 0.3244 & 0.1686 & 0.0755 & 0.0290 & 0.0094 & 0.0025 & 0.0005 & 0.0001 & 0.0000 & 0.0000 & \\
\hline 26 & 0.4230 & 0.2475 & 0.1221 & 0.0522 & 0.0192 & 0.0059 & 0.0015 & 0.0003 & 0. & 0.0000 & 0.0000 \\
\hline 27 & 0.3412 & 0.1849 & 0.0872 & 0.0357 & 0.0125 & 0.0037 & 0.0009 & 0.0002 & 0.0000 & 0.0000 & \\
\hline 28 & 0.4342 & 0.2644 & 0.1360 & 0.0614 & 0.0241 & 0.0081 & 0.0023 & 0.0005 & 0.0001 & 0.0000 & 0 \\
\hline 29 & 0.3564 & 0.2004 & 0.0987 & 0.0428 & 0.0161 & 0.0052 & 0.0014 & 0.0003 & 0.0001 & 0.0000 & \\
\hline 30 & 0.4439 & 0.2802 & 0.1496 & 0.0708 & 0.0294 & 0.0107 & 0.0033 & 0.0009 & 0.0002 & 0.0000 & 0.0000 \\
\hline 31 & 0.3701 & 0.2152 & 0.1102 & 0.0501 & 0.0201 & 0.0070 & 0.0021 & 0.0005 & 0.0001 & 0.0000 & \\
\hline 32 & 0.4521 & 0.2949 & 0.1627 & 0.0801 & 0.0351 & 0.0135 & 0.0046 & 0.0013 & 0.0003 & 0.0001 & 0.0000 \\
\hline 33 & 0.3825 & 0.2293 & 0.1214 & 0.0576 & 0.0243 & 0.0090 & 0.0029 & 0.0008 & 0.0002 & 0.0000 & \\
\hline 34 & 0.4591 & 0.3086 & 0.1754 & 0.0895 & 0.0410 & 0.0167 & 0.0060 & 0.0019 & 0.0005 & 0.0001 & .0000 \\
\hline 35 & 0.3937 & 0.2427 & 0.1325 & 0.0652 & 0.0288 & 0.0113 & 0.0039 & 0.0012 & 0.0003 & 0.0001 & \\
\hline 36 & 0.4651 & 0.3214 & 0.1877 & 0.0989 & 0.0470 & 0.0201 & 0.0076 & 0.0026 & 0.0008 & 0.0002 & 0.0000 \\
\hline 37 & 0.4039 & 0.2554 & 0.1433 & 0.0730 & 0.0336 & 0.0139 & 0.0051 & 0.0017 & 0.0005 & 0.0001 & \\
\hline 38 & 0.4702 & 0.3334 & 0.1995 & 0.1081 & 0.0533 & 0.0237 & 0.0095 & 0.0034 & 0.0011 & 0.0003 & 01 \\
\hline 39 & 0.4130 & 0.2675 & 0.1539 & 0.0807 & 0.0385 & 0.0166 & 0.0064 & 0.0022 & 0.0007 & 0.0002 & \\
\hline 40 & 0.4746 & 0.3446 & 0.2109 & 0.1173 & 0.0596 & 0.0275 & 0.0115 & 0.0043 & 0.0015 & 0.0004 & 0.0001 \\
\hline 41 & 0.4213 & 0.2790 & 0.1641 & 0.0884 & 0.0436 & 0.0195 & 0.0079 & 0.0029 & 0.0009 & 0.0003 & \\
\hline 42 & 0.4783 & 0.3550 & 0.2219 & 0.1263 & 0.0660 & 0.0315 & 0.0137 & 0.0054 & 0.0019 & 0.0006 & 0.0002 \\
\hline 43 & 0.4289 & 0.2900 & 0.1741 & 0.0961 & 0.0488 & 0.0226 & 0.0096 & 0.0037 & 0.0013 & 0.0004 & \\
\hline 44 & 0.4815 & 0.3647 & 0.2324 & 0.1352 & 0.0725 & 0.0357 & 0.0161 & 0.0066 & 0.0025 & 0.0008 & 0.0002 \\
\hline 45 & 0.4357 & 0.3004 & 0.1839 & 0.1038 & 0.0541 & 0.0259 & 0.0114 & 0.0045 & 0.0016 & 0.0005 & \\
\hline 46 & 0.4842 & 0.3738 & 0.2426 & 0.1439 & 0.0789 & 0.0400 & 0.0186 & 0.0079 & 0.0031 & 0.0011 & 0.0003 \\
\hline 47 & 0.4418 & 0.3102 & 0.1934 & 0.1114 & 0.0595 & 0.0293 & 0.0133 & 0.0055 & 0.0021 & 0.0007 & \\
\hline 48 & 0.4865 & 0.3822 & 0.2524 & 0.1524 & 0.0854 & 0.0444 & 0.0213 & 0.0094 & 0.0038 & 0.0014 & 0.0005 \\
\hline 49 & 0.4474 & 0.3196 & 0.2025 & 0.1189 & 0.0649 & 0.0328 & 0.0153 & 0.0066 & 0.0026 & 0.0009 & \\
\hline 50 & 0.4885 & 0.3901 & 0.2618 & 0.1608 & 0.0919 & 0.0489 & 0.0241 & 0.0110 & 0.0046 & 0.0018 & 0.0006 \\
\hline
\end{tabular}


Table IV. $\alpha_{1}\left(0.6 ; c, n_{t}\right)$ of Closed Type (continued), $c=4(1) 24, n_{t}=10(1) 50$.

\begin{tabular}{|c|c|c|c|c|c|c|c|c|c|c|c|}
\hline & $\begin{array}{c}4 \\
(5)\end{array}$ & $\begin{array}{c}6 \\
(7)\end{array}$ & $\begin{array}{c}8 \\
(9)\end{array}$ & $\begin{array}{c}10 \\
\text { (11) }\end{array}$ & $\begin{array}{c}12 \\
(13)\end{array}$ & $\begin{array}{c}14 \\
(15)\end{array}$ & $\begin{array}{c}16 \\
(17)\end{array}$ & $\begin{array}{c}18 \\
(19)\end{array}$ & $\begin{array}{c}20 \\
(21)\end{array}$ & $\begin{array}{c}22 \\
(23)\end{array}$ & 24 \\
\hline 10 & 0.4445 & 0.1864 & 0.0916 & 0.0432 & 0.0197 & 0.0088 & 0.0038 & 0.0016 & 0.0007 & 0.0003 & 0.0001 \\
\hline 11 & 0.3413 & 0.1315 & 0.0632 & 0.0293 & 0.0132 & 0.0058 & 0.0025 & 0.0011 & 0.0005 & 0.0002 & \\
\hline 12 & 0.5150 & 0.2573 & 0.0916 & 0.0432 & 0.0197 & 0.0088 & 0.0038 & 0.0016 & 0.0007 & 0.0003 & 0.00 \\
\hline 13 & 0.4122 & 0.1911 & 0.0632 & 0.0293 & 0.0132 & 0.0058 & 0.0025 & 0011 & 0.0005 & 0.0002 & \\
\hline 14 & 0.5728 & 0.3238 & 0.1399 & 0.0432 & 0.0197 & 0.0088 & 0.0038 & 0.0016 & 0.0007 & 0.0003 & 0.0001 \\
\hline 15 & 0.4741 & 0. 2502 & 0.1012 & 0.0293 & 0.0132 & 0.0058 & 0.0025 & 0.0011 & 0.0005 & 0.0002 & \\
\hline 16 & 0.6202 & 0.3846 & 0.1906 & 0.0725 & 0.0197 & 0.0088 & 0.0038 & 0.0016 & 0.0007 & 0.0003 & 0.0001 \\
\hline 17 & 0.5280 & 0.3070 & 0.1434 & 0.0514 & 0.0132 & 0.0058 & 0.0025 & 0.0011 & 0.0005 & 0.0002 & \\
\hline 18 & 0.6590 & 0.4398 & 0.2415 & 0.1066 & 0.0361 & 0.0088 & 0.0038 & 0.0016 & 0.0007 & 0.0003 & 0.0001 \\
\hline 19 & 0.5748 & 0.3605 & 0.1876 & 0.0784 & 0.0252 & 0.0058 & 0.0025 & 0.0011 & 0.0005 & 0.0002 & \\
\hline 20 & 0.6908 & 0.4895 & 0.2913 & 0.1439 & 0.0571 & 0.0174 & 0.0038 & 0.0016 & 0.0007 & 0.0003 & 0.0001 \\
\hline 21 & 0.6155 & 0.4102 & 0.2323 & 0.1092 & 0.0412 & 0.0120 & 0.0025 & 0.0011 & 0.0005 & 0.0002 & \\
\hline 22 & 0.7168 & 0.5342 & 0.3391 & 0.1831 & 0.0820 & 0.0295 & 0.0082 & 0.0016 & 0.0007 & 0.0003 & 001 \\
\hline 23 & 0.6508 & 0.4562 & 0.2767 & 0.1426 & 0.0610 & 0.0210 & 0.0056 & 0.0011 & 0.0005 & 0.0002 & \\
\hline 24 & 0.7382 & 0.5743 & 0.3844 & 0.2231 & 0.1100 & 0.0450 & 0.0148 & 0.0038 & 0.0007 & 0.0003 & 0.0001 \\
\hline 25 & 0.6814 & 0.4983 & 0.3199 & 0.1778 & 0.0840 & 0.0329 & 0.0104 & 0.0025 & 0.0005 & 0.0002 & \\
\hline 26 & 0.7557 & 0.6102 & 0.4271 & 0.2631 & 0.1403 & 0.0636 & 0.0239 & 0.0073 & 0.0017 & 0.0003 & 0.0001 \\
\hline 27 & 0.7081 & 0.5373 & 0.3615 & 0.2140 & 0.1096 & 0.0477 & 0.0173 & 0.0050 & 0.0011 & 0.0002 & \\
\hline 28 & 0.7700 & 0.6425 & 0.4670 & 0.3025 & 0.1722 & 0.0848 & 0.0355 & 0.0124 & 0.0035 & 0.0008 & 0.001 \\
\hline 29 & 0.7312 & 0.5728 & 0.4012 & 0.2504 & 0.1373 & 0.0651 & 0.0263 & 0.0088 & 0.0024 & 0.0005 & \\
\hline 30 & 0.7818 & 0.6713 & 0.5042 & 0.3409 & 0.2051 & 0.1084 & 0.0496 & 0.0193 & 0.0062 & 0.0016 & 0.0003 \\
\hline 31 & 0.7513 & 0.6053 & 0.4389 & 0.2866 & 0.1664 & 0.0849 & 0.0375 & 0.0141 & 0.0044 & 0.0011 & \\
\hline 32 & 0.7914 & 0.6972 & 0.5388 & 0.3780 & 0.2385 & 0.1338 & 0.0659 & 0.0281 & 0.0102 & 0.0031 & 0.0008 \\
\hline 33 & 0.7687 & 0.6349 & 0.4745 & 0.3222 & 0.1966 & 0.1067 & 0.0508 & 0.0209 & 0.0074 & 0.0022 & \\
\hline 34 & 0.7993 & 0.7204 & 0.5709 & 0.4136 & 0.2720 & 0.1606 & 0.0843 & 0.0389 & 0.0155 & 0.0053 & 0.0015 \\
\hline 35 & 0.7838 & 0.6620 & 0.5080 & 0.3569 & 0.2274 & 0.1301 & 0.0661 & 0.0295 & 0.0114 & 0.0038 & \\
\hline 36 & 0.8057 & 0.7411 & 0.6007 & 0.4476 & 0.3051 & 0.1885 & 0.1045 & 0.0515 & 0.0223 & 0.0084 & 0027 \\
\hline 37 & 0.7970 & 0.6867 & 0.5395 & 0.3906 & 0.2585 & 0.1549 & 0.0833 & 0.0398 & 0.0167 & 0.0061 & \\
\hline 38 & 0.8110 & 0.7597 & 0.6283 & 0.4800 & 0.3378 & 0.2171 & 0.1263 & 0.0659 & 0.0306 & 0.0125 & 0.0044 \\
\hline 39 & 0.8084 & 0.7093 & 0.5690 & 0.4231 & 0.2895 & 0.1807 & 0.1021 & 0.0518 & 0.0233 & 0.0092 & \\
\hline 40 & 0.8154 & 0.7763 & 0.6537 & 0.5107 & 0.3696 & 0.2460 & 0.1493 & 0.0820 & 0.0404 & 0.0177 & 0.0068 \\
\hline 41 & 0.8183 & 0.7299 & 0.5966 & 0.4542 & 0.3202 & 0.2073 & 0.1224 & 0.0653 & 0.0313 & 0.0133 & \\
\hline 42 & 0.8189 & 0.7913 & 0.6773 & 0.5397 & 0.4006 & 0.2750 & 0.1733 & 0.0996 & 0.0517 & 0.0241 & 0.01 .00 \\
\hline 43 & 0.8269 & 0.7487 & 0.6224 & 0.4841 & 0.3504 & 0.2343 & 0.1438 & 0.0804 & 0.0407 & 0.0185 & \\
\hline 44 & 0.8218 & 0.8046 & 0.6991 & 0.5671 & 0.4306 & 0.3040 & 0.1981 & 0.1185 & 0.0645 & 0.0318 & 41 \\
\hline 45 & 0.8344 & 0.7658 & 0.6465 & 0.5125 & 0.3799 & 0.2616 & 0.1663 & 0.0969 & 0.0514 & 0.0247 & \\
\hline 46 & 0.8242 & 0.8166 & 0.7192 & 0.5930 & 0.4595 & 0.3326 & 0.2235 & 0.1385 & 0.0787 & 0.0407 & 91 \\
\hline 47 & 0.8409 & 0.7815 & 0.6690 & 0.5396 & 0.4087 & 0.2890 & 0.1895 & 0.1146 & 0.0635 & 0.0321 & \\
\hline 48 & 0.8262 & 0.8273 & 0.7378 & 0.6173 & 0.4872 & 0.3608 & 0.2492 & 0.1595 & 0.0942 & 0.0509 & 0.0251 \\
\hline 49 & 0.8465 & 0.7958 & 0.6900 & 0.5653 & 0.4367 & 0.3162 & 0.2133 & 0.1334 & 0.0769 & 0.0406 & \\
\hline 50 & 0.8278 & 0.8369 & 0.7550 & 0.6402 & 0.5139 & 0.3885 & 0.2750 & 0.1813 & 0.1108 & 0.0624 & 0.0026 \\
\hline
\end{tabular}


Table IV. $\alpha_{1}\left(0.7 ; c, n_{t}\right)$ of Closed Type (continued), $c=4(1) 24, n_{t}=10(1) 50$.

\begin{tabular}{|c|c|c|c|c|c|c|c|c|c|c|c|}
\hline & $\begin{array}{c}4 \\
(5)\end{array}$ & $\begin{array}{c}6 \\
(7) \\
\end{array}$ & $\begin{array}{c}8 \\
(9)\end{array}$ & $\begin{array}{c}10 \\
(11)\end{array}$ & $\begin{array}{c}12 \\
(13) \\
\end{array}$ & $\begin{array}{c}14 \\
(15)\end{array}$ & $\begin{array}{c}16 \\
(17)\end{array}$ & $\begin{array}{c}18 \\
(19)\end{array}$ & $\begin{array}{c}20 \\
(21)\end{array}$ & $\begin{array}{c}22 \\
(23)\end{array}$ & 24 \\
\hline 10 & 0.6968 & 0.4060 & 0.2664 & 0.1685 & 0.1037 & 0.0623 & 0.0368 & 0.0214 & 0.0122 & 0.0069 & 0.0039 \\
\hline 11 & 0.6095 & 0.3305 & 0.2127 & 0.1326 & 0.0806 & 0.0480 & 0.0281 & 0.0162 & 0.0092 & 0.0052 & \\
\hline 12 & 0.7733 & 0.5258 & 0.2664 & 0.1685 & 0.1037 & 0.0623 & 0.0368 & 0.0214 & 0.0122 & 0.0069 & 0.0039 \\
\hline 13 & 0.6994 & 0.4480 & 0.2127 & 0.1326 & 0.0806 & 0.0480 & 0.0281 & 0.0162 & 0.0092 & 0.0052 & \\
\hline 14 & 0.8282 & 0.6240 & 0.3774 & 0.1685 & 0.1037 & 0.0623 & 0.0368 & 0.0214 & 0.0122 & 0.0069 & 0.0039 \\
\hline 15 & 0.7680 & 0.5500 & 0.3147 & 0.1326 & 0.0806 & 0.0480 & 0.0281 & 0.0162 & 0.0092 & 0.0052 & \\
\hline 16 & 0.8676 & 0.7027 & 0.4794 & 0.2601 & 0.1037 & 0.0623 & 0.0368 & 0.0214 & 0.0122 & 0.0069 & 0.0039 \\
\hline 17 & 0.8203 & 0.6357 & 0.4136 & 0.2132 & 0.0806 & 0.0480 & 0.0281 & 0.0162 & 0.0092 & 0.0052 & \\
\hline 18 & 0.8958 & 0.7651 & 0.5691 & 0.3535 & 0.1734 & 0.0623 & 0.0368 & 0.0214 & 0.0122 & 0.0069 & 0.0039 \\
\hline 19 & 0.8600 & 0.7063 & 0.5044 & 0.2995 & 0.1401 & 0.0480 & 0.0281 & 0.0162 & 0.0092 & 0.0052 & \\
\hline 20 & 0.9161 & 0.81 .44 & 0.6457 & 0.4429 & 0.2516 & 0.1124 & 0.0368 & 0.0214 & 0.0122 & 0.0069 & 0.0039 \\
\hline 21 & 0.8902 & 0.7638 & 0.5849 & 0.3855 & 0.2099 & 0.0897 & 0.0281 & 0.0162 & 0.0092 & 0.0052 & \\
\hline 22 & 0.9306 & 0.8531 & 0.71 .01 & 0.5251 & 0.3328 & 0.1738 & 0.0712 & 0.0214 & 0.0122 & 0.0069 & 0.0039 \\
\hline 23 & 0.9132 & 0.8103 & 0.6546 & 0.4674 & 0.2851 & 0.1431 & 0.0563 & 0.0162 & 0.0092 & 0.0052 & \\
\hline 24 & 0.9410 & 0.8835 & 0.7636 & 0.5985 & 0.4127 & 0.2425 & 0.1170 & 0.0442 & 0.0122 & 0.0069 & 0.0039 \\
\hline 25 & 0.9306 & 0.8477 & 0.7140 & 0.5427 & 0.3617 & 0.2049 & 0.0952 & 0.0346 & 0.0092 & 0.0052 & \\
\hline 26 & 0.9485 & 0.9073 & 0.8076 & 0.6627 & 0.4884 & 0.3146 & 0.1720 & 0.0770 & 0.0270 & 0.0069 & 0.0039 \\
\hline 27 & 0.9439 & 0.8777 & 0.7641 & 0.6104 & 0.4363 & 0.2718 & 0.1435 & 0.0620 & 0.0210 & 0.0052 & \\
\hline 28 & 0.9538 & 0.9260 & 0.8437 & 0.7180 & 0.5582 & 0.3869 & 0.2333 & 0.1190 & 0.0497 & 0.0163 & 0.0039 \\
\hline 29 & 0.9539 & 0.9017 & 0.8060 & 0.6700 & 0.5068 & 0.3409 & 0.1990 & 0.0982 & 0.0397 & 0.0125 & \\
\hline 30 & 0.9576 & 0.9407 & 0.8731 & 0.7652 & 0.6211 & 0.4570 & 0.2983 & 0.1688 & 0.0807 & 0.0315 & 0.0097 \\
\hline 31 & 0.9616 & 0.9210 & 0.8407 & 0.7220 & 0.5719 & 0.4094 & 0.2595 & 0.1424 & 0.0659 & 0.0250 & \\
\hline 32 & 0.9604 & 0.9522 & 0.8970 & 0.8051 & 0.6769 & 0.5231 & 0.3644 & 0.2243 & 0.11 .194 & 0.0536 & 0.0197 \\
\hline 33 & 0.9674 & 0.9363 & 0.8694 & 0.7666 & 0.6308 & 0.4755 & 0.3224 & 0.1929 & 0.0997 & 0.0435 & \\
\hline 34 & 0.9624 & 0.9612 & 0.9164 & 0.8386 & 0.7259 & 0.5842 & 0.4296 & 0.2835 & 0.1649 & 0.0828 & 0.0351 \\
\hline 35 & 0.9718 & 0.9486 & 0.8931 & 0.8048 & 0.6834 & 0.5378 & 0.3858 & 0.2479 & 0.1403 & 0.0685 & \\
\hline 36 & 0.9638 & 0.9683 & 0.9322 & 0.8666 & 0.7684 & 0.6397 & 0.4922 & 0.3444 & 0.2156 & 0.1188 & 0.0564 \\
\hline 37 & 0.9751 & 0.9584 & 0.9125 & 0.8371 & 0.7298 & 0.5955 & 0.4479 & 0.3058 & 0.1866 & 0.1001 & \\
\hline 38 & 0.9648 & 0.9738 & 0.9449 & 0.8899 & 0.8049 & 0.6895 & 0.5512 & 0.4052 & 0.2700 & 0.1606 & 0.0839 \\
\hline 39 & 0.9777 & 0.9663 & 0.9285 & 0.8644 & 0.7703 & 0.6480 & 0.5074 & 0.3647 & 0.2372 & 0.1376 & \\
\hline 40 & 0.9655 & 0.9781 & 0.9553 & 0.9093 & 0.8362 & 0.7336 & 0.6058 & 0.4646 & 0.3264 & 0.2073 & 0.1173 \\
\hline 41 & 0.9796 & 0.9725 & 0.9415 & 0.8873 & 0.8054 & 0.6953 & 0.5634 & 0.4231 & 0.2907 & 0.1803 & \\
\hline 42 & 0.9660 & 0.9815 & 0.9636 & 0.9253 & 0.8628 & 0.7724 & 0.6557 & 0.5213 & 0.3834 & 0.2576 & 0.1561 \\
\hline 43 & 0.9811 & 0.9775 & 0.9522 & 0.9065 & 0.8356 & 0.7374 & 0.6154 & 0.4800 & 0.3457 & 0.2271 & \\
\hline 44 & 0.9664 & 0.9842 & 0.9704 & 0.9385 & 0.8853 & 0.8062 & 0.7008 & 0.5748 & 0.4397 & 0.3101 & 0.1994 \\
\hline 45 & 0.9822 & 0.9815 & 0.9609 & 0.9225 & 0.8615 & 0.7745 & 0.6630 & 0.5342 & 0.4008 & 0.2769 & \\
\hline 46 & 0.9667 & 0.9863 & 0.9758 & 0.9494 & 0.9042 & 0.8354 & 0.7411 & 0.6244 & 0.4942 & 0.3636 & 0.2461 \\
\hline 47 & 0.9831 & 0.9847 & 0.9681 & 0.9359 & 0.8836 & 0.8071 & 0.7061 & 0.5853 & 0.4550 & 0.3284 & \\
\hline 48 & 0.9669 & 0.9879 & 0.9803 & 0.9584 & 0.9202 & 0.8607 & 0.7768 & 0.6698 & 0.5462 & 0.4170 & 0.2952 \\
\hline 49 & 0.9837 & 0.9873 & 0.9739 & 0.9470 & 0.9023 & 0.8355 & 0.7447 & 0.6328 & 0.5075 & 0.3805 & \\
\hline 50 & 0.9670 & 0.9892 & 0.9838 & 0.9658 & 0.9336 & 0.8823 & 0.8083 & 0.7111 & 0.5952 & 0.4694 & 0.3456 \\
\hline
\end{tabular}


Table IV. $\alpha_{1}\left(0.8 ; c, n_{t}\right)$ of Closed Type (continued), $c=4(1) 24, n_{t}=10(1) 50$.

\begin{tabular}{|c|c|c|c|c|c|c|c|c|c|c|c|}
\hline & $\begin{array}{c}4 \\
(5)\end{array}$ & $\begin{array}{c}6 \\
(7)\end{array}$ & $\begin{array}{c}8 \\
(9)\end{array}$ & $\begin{array}{c}10 \\
(11)\end{array}$ & $\begin{array}{c}12 \\
(13)\end{array}$ & $\begin{array}{c}14 \\
(15)\end{array}$ & $\begin{array}{c}16 \\
(17)\end{array}$ & $\begin{array}{c}18 \\
(19)\end{array}$ & $\begin{array}{c}20 \\
(21)\end{array}$ & $\begin{array}{c}22 \\
(23)\end{array}$ & 24 \\
\hline 10 & 0.8991 & 0.6950 & 0.5715 & 0.4578 & 0.3590 & 0.2765 & 0.2097 & 0.1571 & 0.1163 & 0.0853 & 0.0620 \\
\hline 11 & 0.8583 & 0.6325 & 0.5130 & 0.4064 & 0.3157 & 0.2412 & 0.1818 & 0.1353 & 0.0997 & 0.0728 & \\
\hline 12 & 0.9431 & 0.8131 & 0.5715 & 0.4578 & 0.3590 & 0.2765 & 0.2097 & 0.1571 & 0.1163 & 0.0853 & 0.0620 \\
\hline 13 & 0.9173 & 0.7648 & 0.5130 & 0.4064 & 0.3157 & 0.2412 & 0.1818 & 0.1353 & 0.0997 & 0.0728 & \\
\hline 14 & 0.9672 & 0.8868 & 0.7144 & 0.4578 & 0.3590 & 0.2765 & 0.2097 & 0.1571 & 0.1163 & 0.0853 & 0.0620 \\
\hline 15 & 0.9517 & 0.8523 & 0.6631 & 0.4064 & 0.3157 & 0.2412 & 0.1818 & 0.1353 & 0.0997 & 0.0728 & \\
\hline 16 & 0.9803 & 0.9318 & 0.8145 & 0.6118 & 0.3590 & 0.2765 & 0.2097 & 0.1571 & 0.1163 & 0.0853 & 0.0620 \\
\hline 17 & 0.9716 & 0.9084 & 0.7739 & 0.5612 & 0.3157 & 0.2412 & 0.1818 & 0.1353 & 0.0997 & 0.0728 & \\
\hline 18 & 0.9875 & 0.9590 & 0.8815 & 0.7314 & 0.5121 & 0.2765 & 0.2097 & 0.1571 & 0.1163 & 0.0853 & 0.0620 \\
\hline 19 & 0.9831 & 0.9435 & 0.8515 & 0.6875 & 0.4650 & 0.2412 & 0.1818 & 0.1353 & 0.0997 & 0.0728 & \\
\hline 20 & 0.9914 & 0.9754 & 0.9251 & 0.8187 & 0.6430 & 0.4202 & 0.2097 & 0.1571 & 0.1163 & 0.0853 & 0.0620 \\
\hline 21 & 0.9898 & 0.9654 & 0.9038 & 0.7836 & 0.5985 & 0.3781 & 0.1818 & 0.1353 & 0.0997 & 0.0728 & \\
\hline 22 & 0.9935 & 0.9852 & 0.9531 & 0.8798 & 0.7465 & 0.5544 & 0.3389 & 0.1571 & 0.1163 & 0.0853 & 20 \\
\hline 23 & 0.9937 & 0.9788 & 0.9384 & 0.8531 & 0.7081 & 0.5113 & 0.3025 & 0.1353 & 0.0997 & 0.0728 & \\
\hline 24 & 0.9947 & 0.9911 & 0.9707 & 0.9213 & 0.8241 & 0.6687 & 0.4695 & 0.2691 & 0.1163 & 0.0853 & 0.0620 \\
\hline 25 & 0.9959 & 0.9870 & 0.9608 & 0.9019 & 0.7930 & 0.6289 & 0.4294 & 0.2385 & 0.0997 & 0.0728 & \\
\hline 26 & 0.9953 & 0.9946 & 0.9818 & 0.9491 & 0.8801 & 0.7602 & 0.5890 & 0.3913 & 0.2108 & 0.0853 & 0.0620 \\
\hline 27 & 0.9972 & 0.9921 & 0.9753 & 0.9353 & 0.8561 & 0.7260 & 0.5495 & 0.3552 & 0.1857 & 0.0728 & \\
\hline 28 & 0.9957 & 0.9967 & 0.9887 & 0.9673 & 0.9194 & 0.8301 & 0.6907 & 0.5106 & 0.3213 & 0.1631 & 0620 \\
\hline 29 & 0.9380 & 0.9951 & 0.9844 & 0.9577 & 0.9016 & 0.8022 & 0.6547 & 0.4727 & 0.2896 & 0.1429 & \\
\hline 30 & 0.9959 & 0.9979 & 0.9930 & 0.9791 & 0.9465 & 0.8817 & 0.7727 & 0.6183 & 0.4361 & 0.2603 & 0.1249 \\
\hline 31 & 0.9984 & 0.9970 & 0.9902 & 0.9726 & 0.9335 & 0.8599 & 0.7418 & 0.5818 & 0.4009 & 0.2332 & \\
\hline 32 & 0.9960 & 0.9986 & 0.9957 & 0.9867 & 0.9647 & 0.9188 & 0.8363 & 0.7093 & 0.5457 & 0.3674 & 0.2083 \\
\hline 33 & 0.9987 & 0.9982 & 0.9939 & 0.9825 & 0.9556 & 0.9023 & 0.8110 & 0.6770 & 0.5100 & 0.3356 & \\
\hline 34 & 0.9960 & 0.9991 & 0.9973 & 0.9916 & 0.9770 & 0.9449 & 0.8840 & 0.7842 & 0.6436 & 0.4751 & 0.3056 \\
\hline 35 & 0.9988 & 0.9989 & 0.9962 & 0.9886 & 0.9707 & 0.9327 & 0.8641 & 0.7561 & 0.6099 & 0.4412 & \\
\hline 36 & 0.9961 & 0.9994 & 0.9983 & 0.9947 & 0.9850 & 0.9630 & 0.9190 & 0.8425 & 0.7268 & 0.5762 & 0.4085 \\
\hline 37 & 0.9989 & 0.9993 & 0.9976 & 0.9927 & 0.9806 & 0.9542 & 0.9037 & 0.8193 & 0.6967 & 0.5426 & \\
\hline 38 & 0.9961 & 0.9995 & 0.9990 & 0.9966 & 0.9903 & 0.9753 & 0.9441 & 0.8868 & 0.7948 & 0.6659 & 0.5095 \\
\hline 39 & 0.9990 & 0.9995 & 0.9885 & 0.9954 & 0.9873 & 0.9691 & 0.9326 & 0.8684 & 0.7690 & 0.6346 & \\
\hline 40 & 0.9961 & 0.9996 & 0.9994 & 0.9979 & 0.9938 & 0.9837 & 0.9618 & 0.9198 & 0.8485 & 0.7421 & 0.6031 \\
\hline 41 & 0.9990 & 0.9997 & 0.9991 & 0.9971 & 0.991 .7 & 0.9793 & 0.9534 & 0.9055 & 0.8273 & 0.7143 & \\
\hline 42 & 0.9961 & 0.9997 & 0.9996 & 0.9987 & 0.9960 & 0.9893 & 0.9741 & 0.9438 & 0.8899 & 0.8047 & 0.6858 \\
\hline 43 & 0.9990 & 0.9998 & 0.9994 & 0.9981 & 0.9947 & 0.9862 & 0.9681 & 0.9330 & 0.8728 & 0.7809 & \\
\hline 44 & 0.9961 & 0.9997 & 0.9997 & 0.9992 & 0.9974 & 0.9930 & 0.9826 & 0.9611 & 0.9210 & 0.8545 & 0.7560 \\
\hline 45 & 0.9990 & 0.9998 & 0.9996 & 0.9988 & 0.9965 & 0.9909 & 0.9783 & 0.9530 & 0.9077 & 0.8348 & \\
\hline 46 & 0.9961 & 0.9997 & 0.9998 & 0.9995 & 0.9984 & 0.9954 & 0.9884 & 0.9732 & 0.9440 & 0.8931 & 0.8139 \\
\hline 47 & 0.9990 & 0.9998 & 0.9998 & 0.9993 & 0.9978 & 0.9940 & 0.9853 & 0.9674 & 0.9338 & 0.8773 & \\
\hline 48 & 0.9961 & 0.9997 & 0.9999 & 0.9997 & 0.9990 & 0.9970 & 0.9923 & 0.9818 & 0.9607 & 0.9225 & .8602 \\
\hline 49 & 0.9990 & 0.9999 & 0.9999 & 0.9995 & 0.9986 & 0.9961 & 0.9902 & 0.9775 & 0.9530 & 0.9100 & \\
\hline 50 & 0.9961 & 0.9997 & 0.9999 & 0.9998 & 0.9993 & 0.9981 & 0.9949 & 0.9876 & 0.9726 & 0.9444 & 0.8964 \\
\hline
\end{tabular}




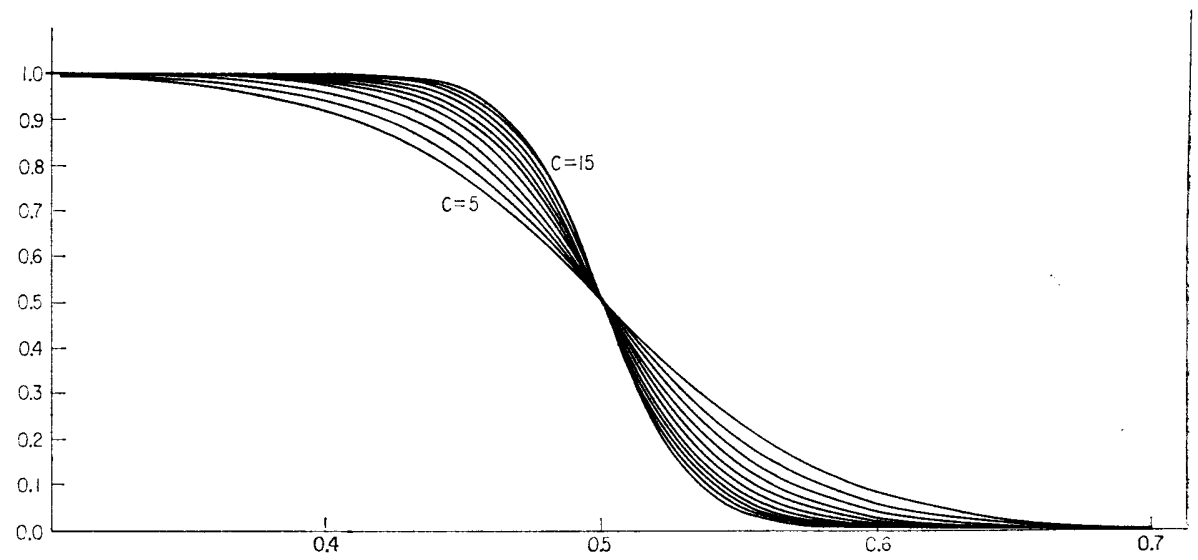

Fig. I. Curves for the probabilities $\alpha_{3}^{*}(p)$ of Open Types.

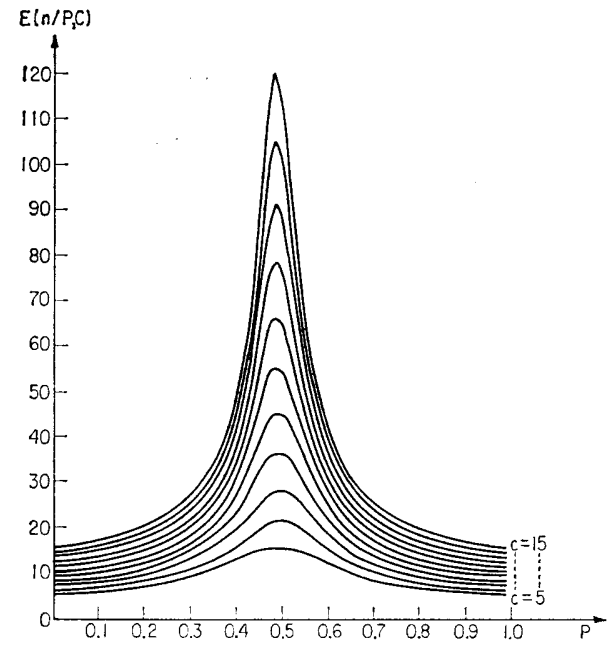

Fig. II. Curves for the average sampling favorable pair numbers of Open Types.

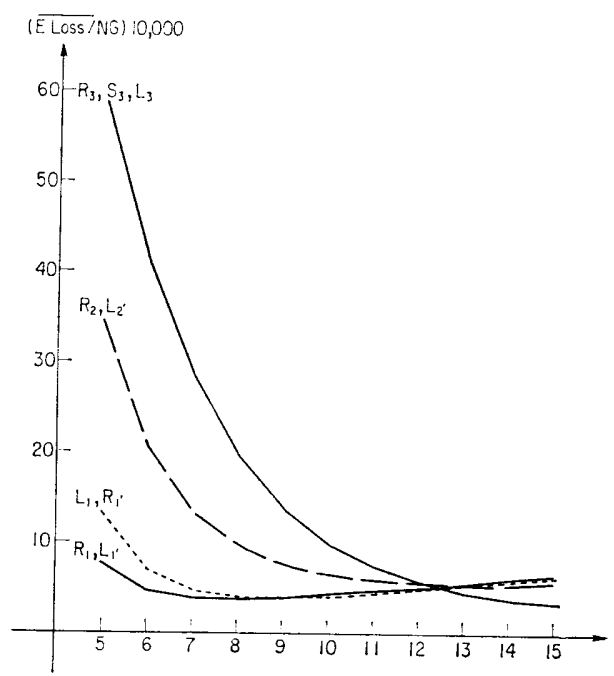

Fig. III. $\overline{\text { E LOSS }} / \mathrm{NG}$ of Open Types. 


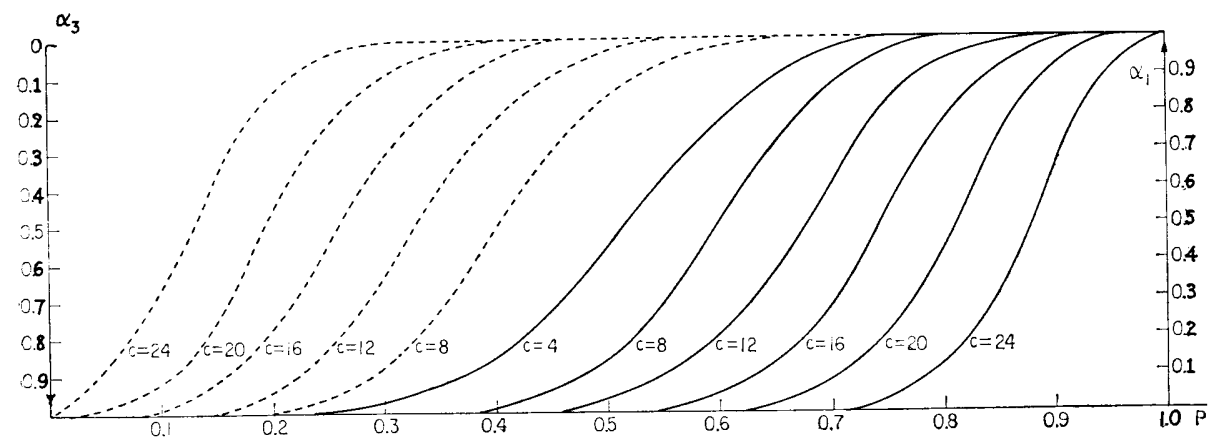

Fig. IV. Monograph of $\alpha_{1}\left(p ; c, n_{t}\right)$ and $\alpha_{3}\left(p ; c, n_{t}\right)$ for $n_{t}=30$.

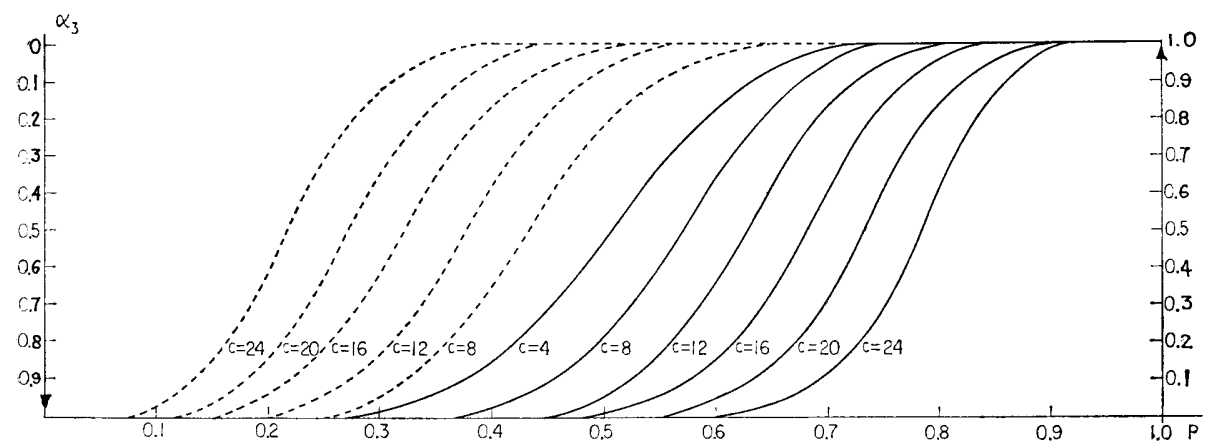

Fig. IV. Monograph of $\alpha_{1}\left(p ; c, n_{t}\right)$ and $\alpha_{3}\left(p ; c, n_{t}\right)$ for $n_{t}=40$.

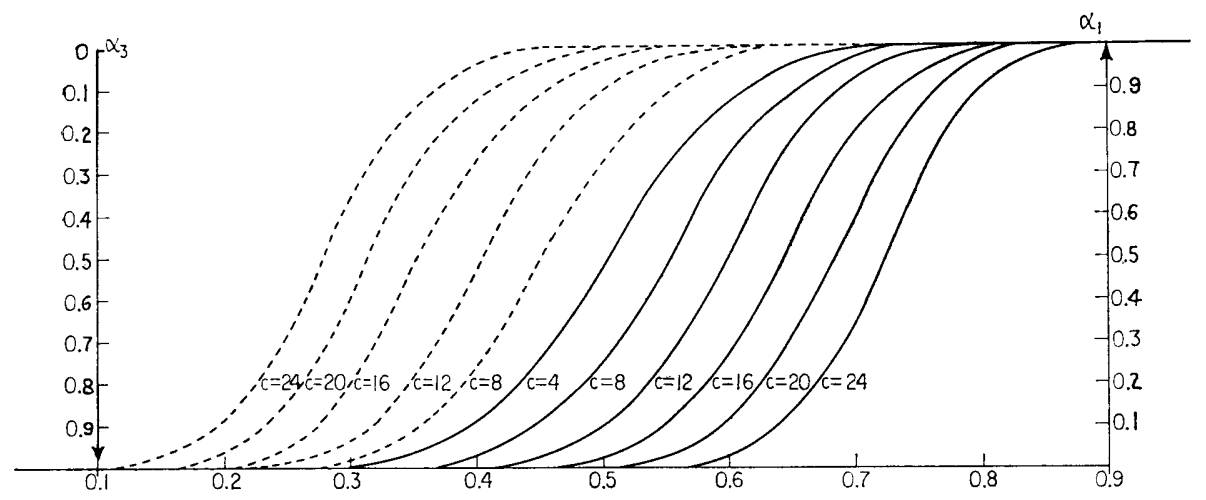

Fig. IV. Monograph of $\alpha_{1}\left(p ; c, n_{t}\right)$ and $\alpha_{3}\left(p ; c, n_{t}\right)$ for $n_{t}=50$. 


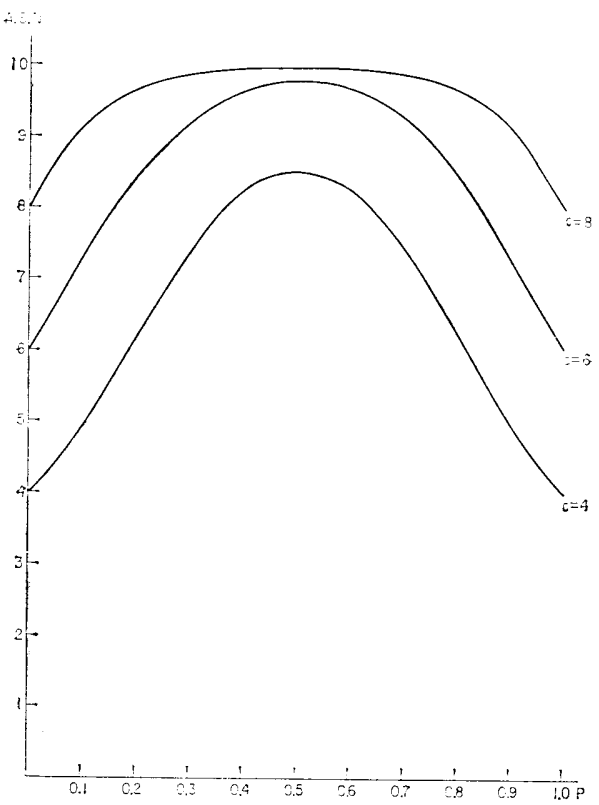

Fig. $V_{1}$. Curves for ASN of Closed Type, Unwedged Design (continued), $n_{t}=10, c=4(2) 8$.

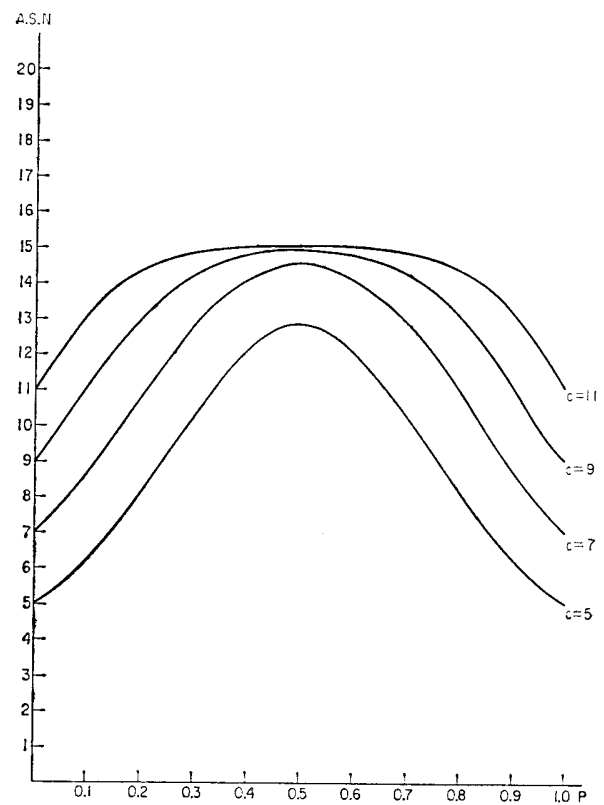

Fig. $V_{1}$. Curves for ASN of Closed Type, Unwedged Design (continued), $n_{t}=15, c=5(2) 11$.

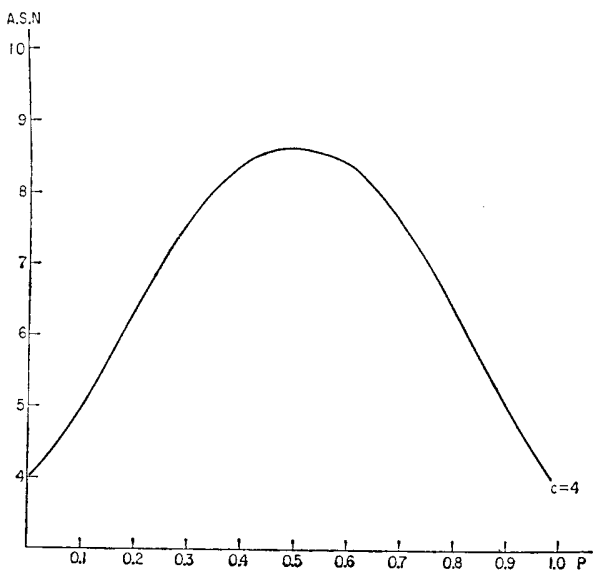

Fig. $V_{2}$. Curves for ASN of Closed Type, Wedged Design (continued), $n_{t}=10, c=4$.

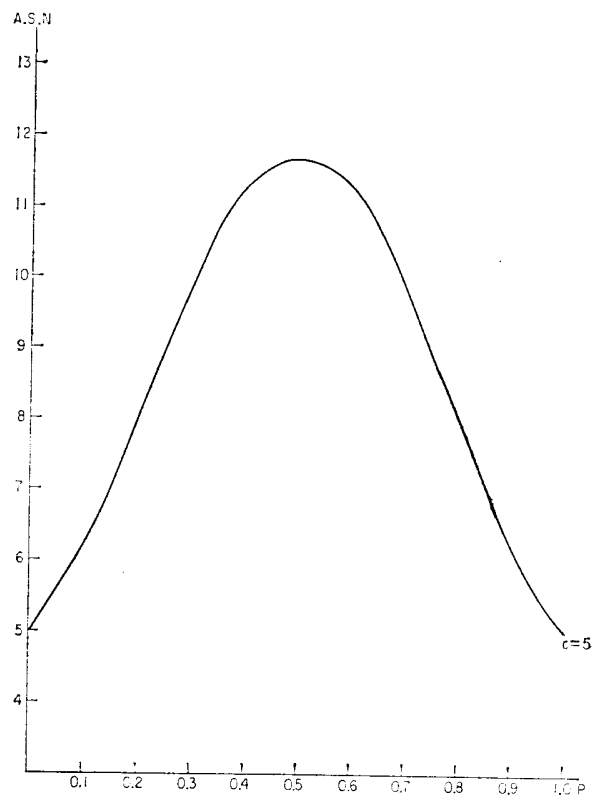

Fig. $\mathrm{V}_{2}$. Curves for ASN of Closed Type, Wedged Design (continued), $n_{t}=15, c=5$. 


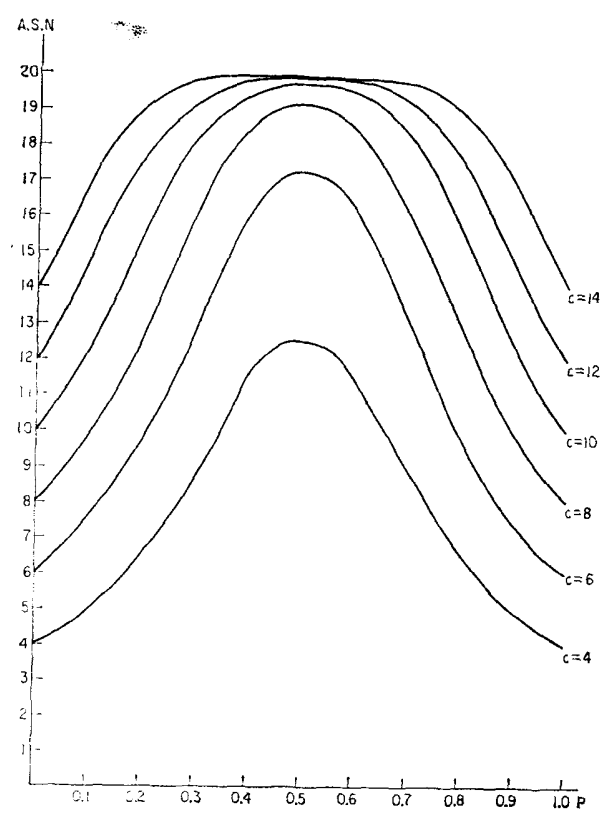

Fig. $V_{1}$. Curves for ASN of Closed Type, Unwedged Design (continued), $n_{t}=20, c=4(2) 14$.

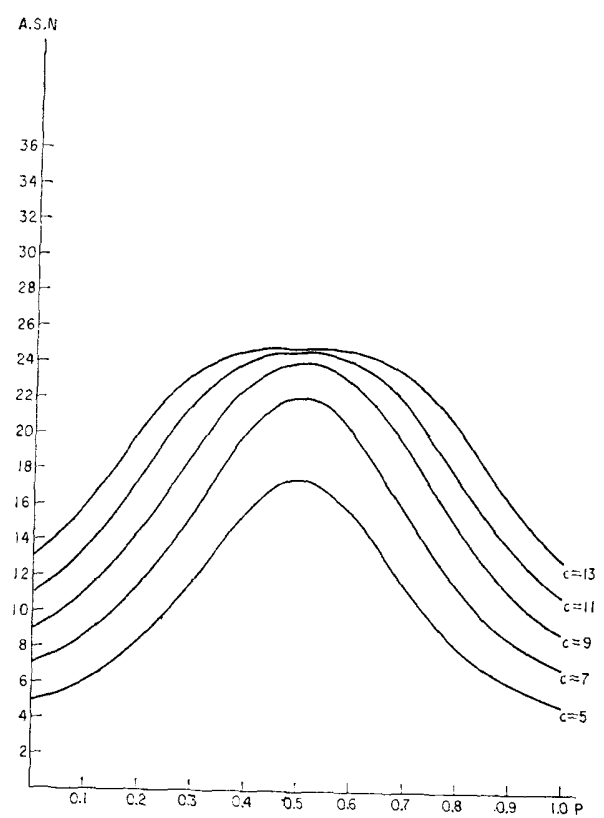

Fig. $V_{1}$. Curves for ASN of Closed Type, Unwedged Design (continued), $n_{t}=25, c=5(2) 13$.

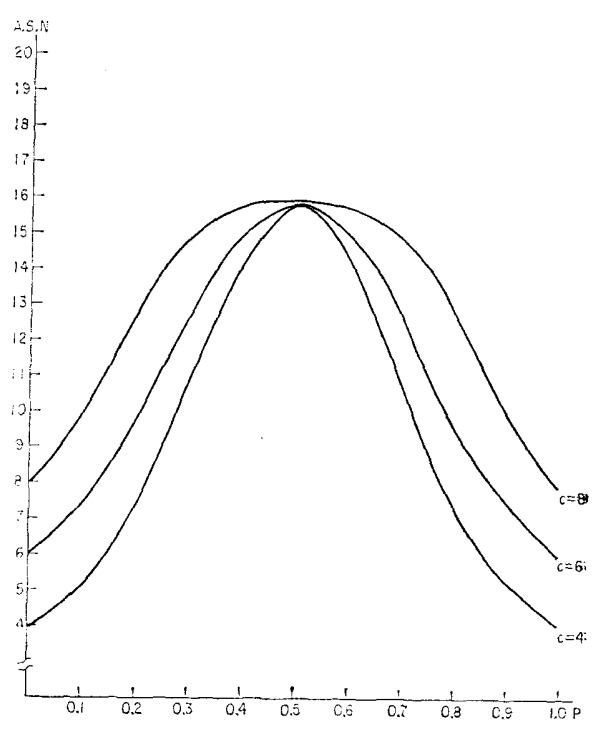

Fig. $\mathrm{V}_{2}$. Curves for ASN of Closed Type, Wedged Design (continued), $n_{t}=20, c=4(2) 8$.

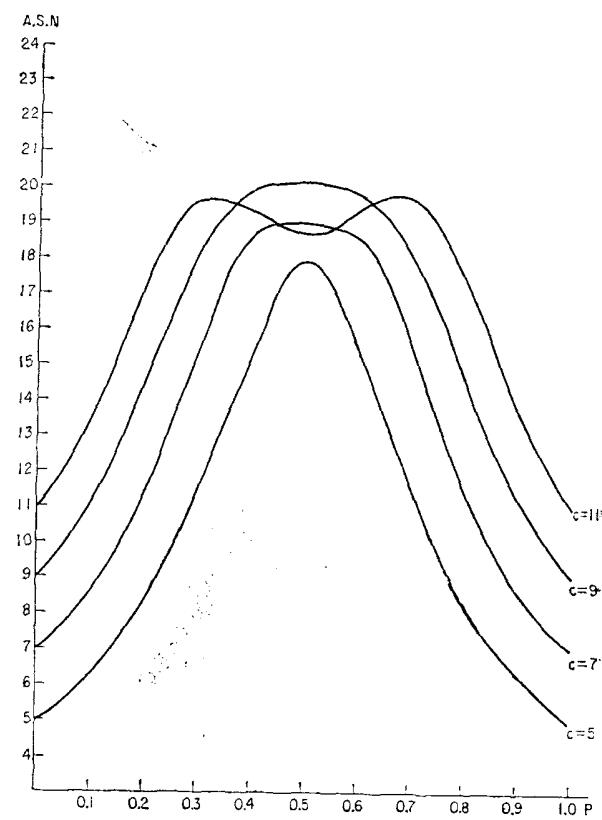

Fig. $\mathrm{V}_{2}$. Curves for ASN of Closed Type, Wedged Design (continued), $n_{t}=25, c=5(2) 11$. 


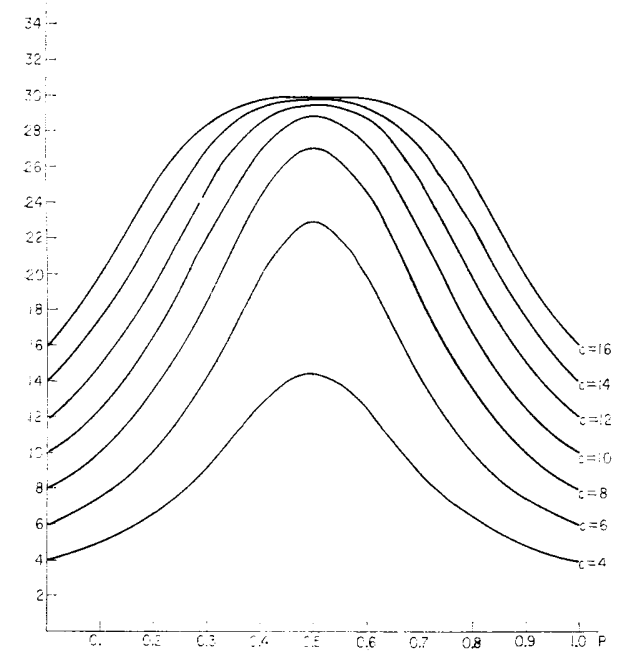

Fig. $V_{1}$. Curves for ASN of Closed Type, Unwedged Design (continued), $n_{t}=30, c=4(2) 16$.

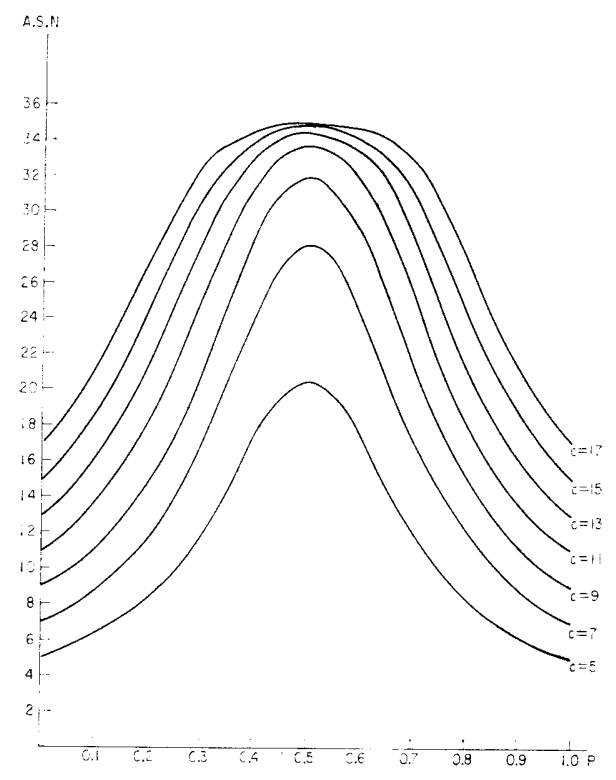

Fig. $V_{1}$. Curves for ASN of Closed Type, Unwedged Design (continued), $n_{t}=35, c=5(2) 17$.

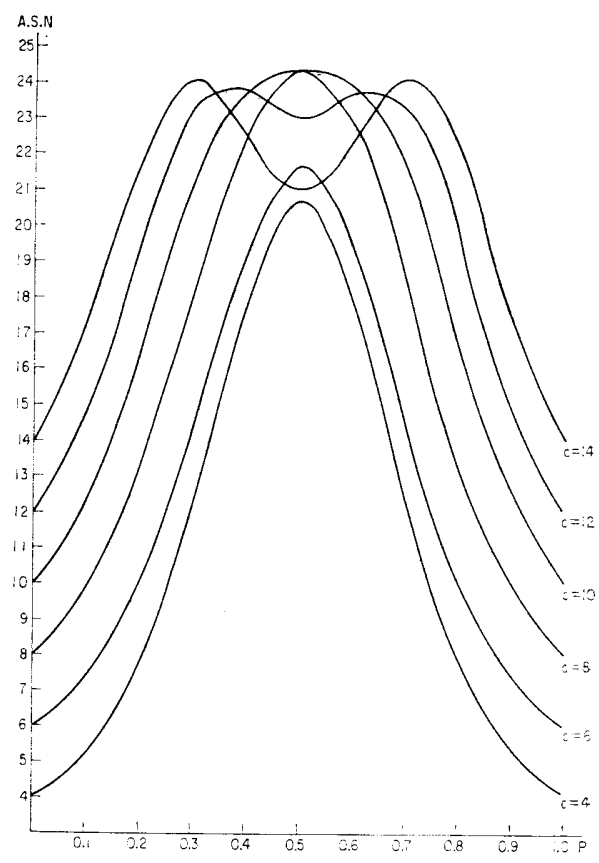

Fig. $V_{2}$. Curves for ASN of Closed Type, Wedged Design (continued), $n_{t}=30, c=4(2) 14$.

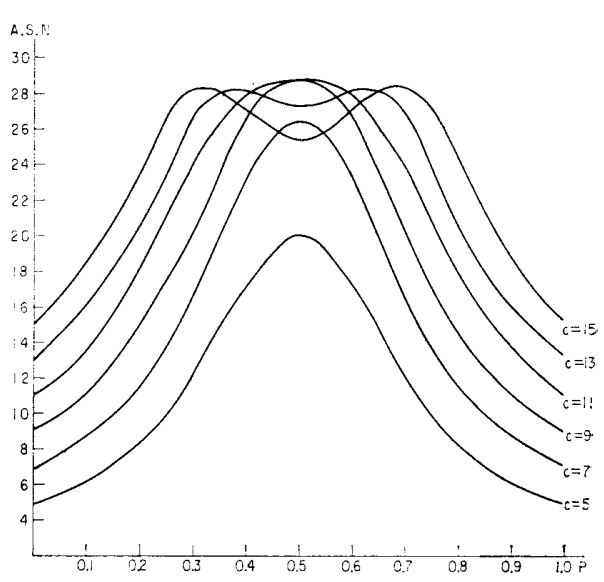

Fig. $V_{2}$. Curves for ASN of Closed Type, Wedged Design (continued), $n_{t}=35, c=5(2) 15$. 


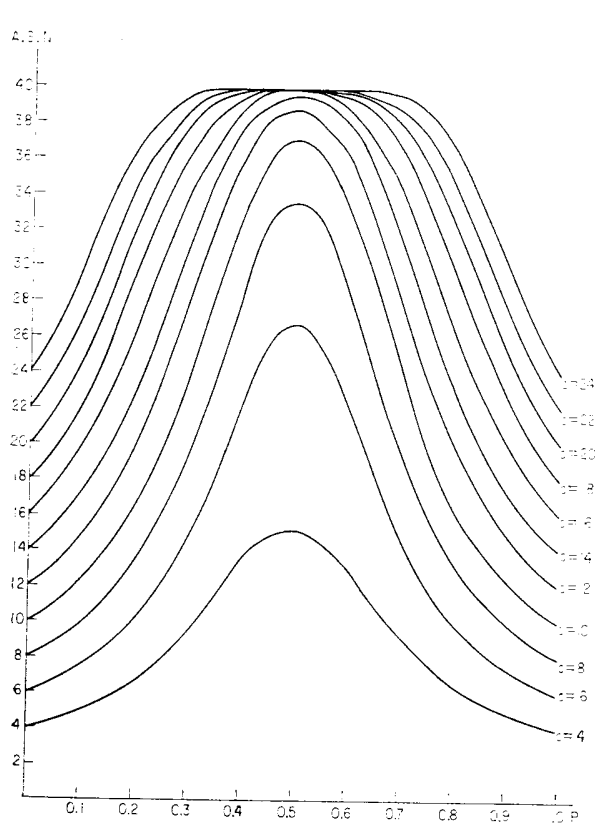

Fig. $V_{1}$. Curves for ASN of Closed Type, Unwedged Design (continued), $n_{t}=40, c=4(2) 24$.

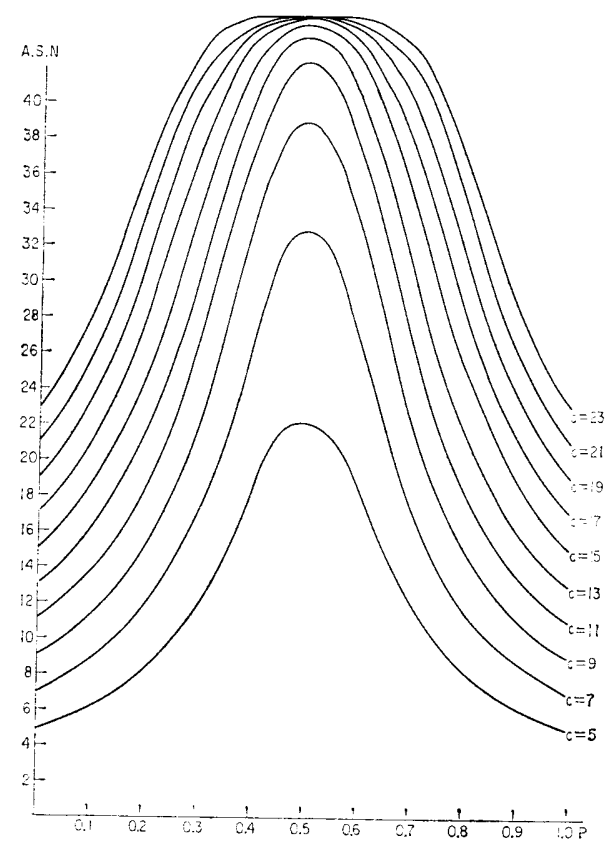

Fig. $V_{1}$. Curves for ASN of Closed Type, Unwedged Design (continued), $n_{t}=45, c=5(2) 23$.

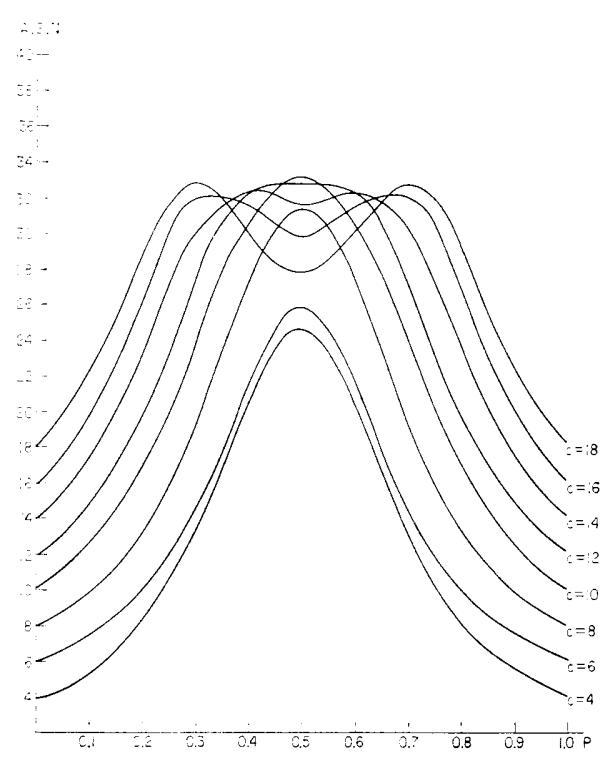

Fig. $V_{2}$. Curves for ASN of Closed Type, Wedged Design (continued), $n_{t}=40, c=4(2) 18$.

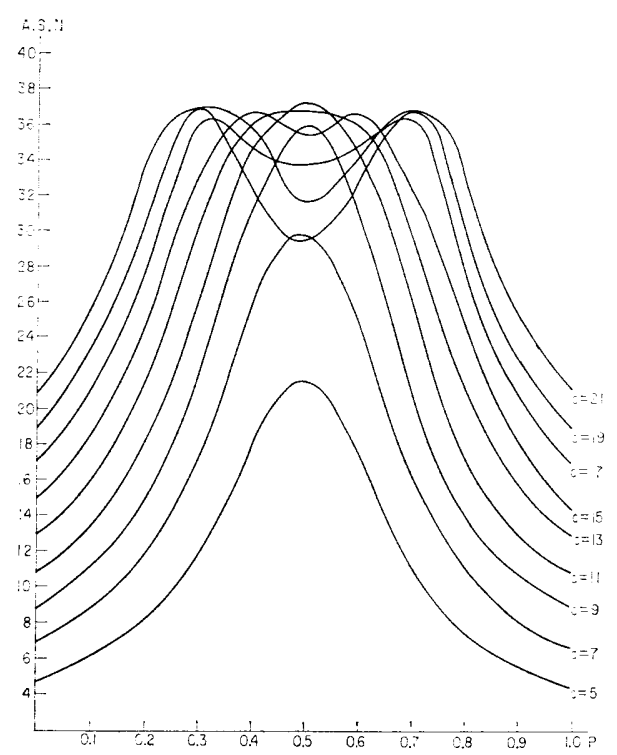

Fig. $\mathrm{V}_{2}$. Curves for ASN of Closed Type, Wedged Design (continued), $n_{t}=45, c=5(2) 21$. 


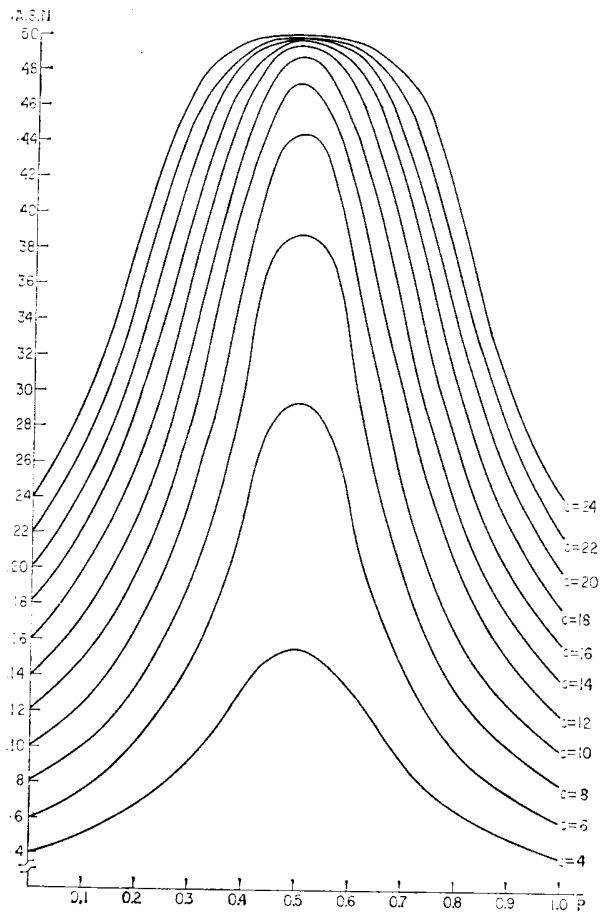

Fig. $V_{1}$. Curves for ASN of Closed Type, Unwedged Design (continued), $n_{t}=50, c=4(2) 24$.

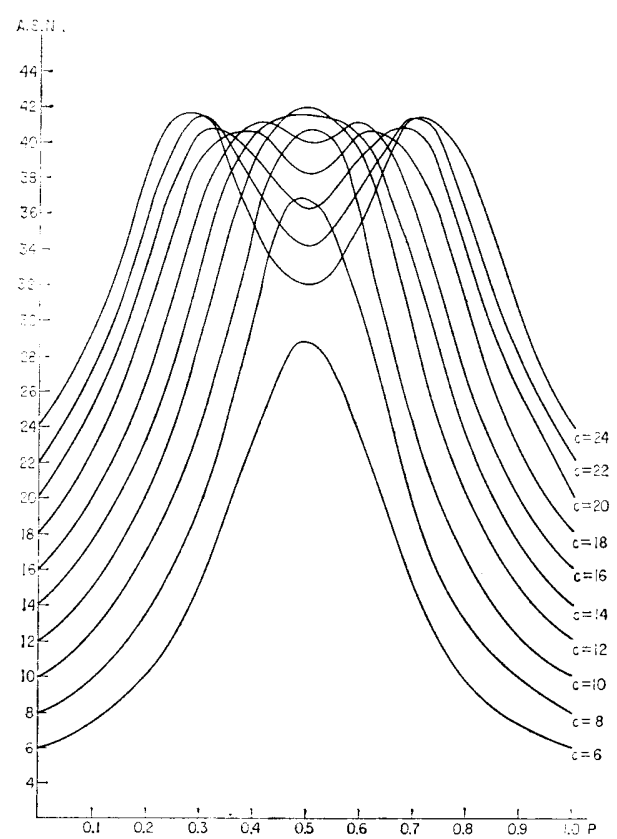

Fig. $V_{2}$. Curves for ASN of Closed Type, Wedged Design (continued), $n_{t}=50, c=6(2) 24$. 


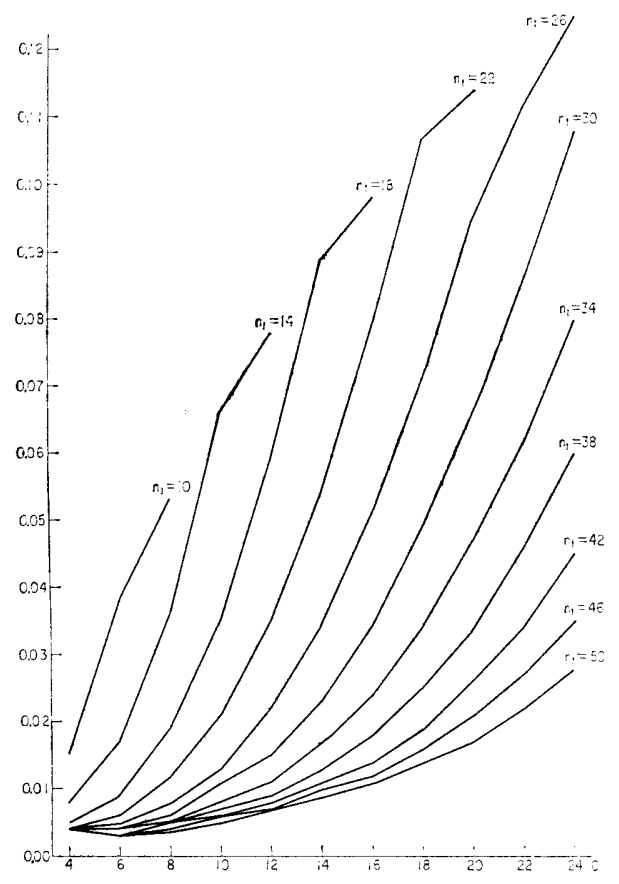

Fig. $\mathrm{VI}_{1}, \overline{\mathrm{E} \mathrm{LOSS}} / \mathrm{NG}$, Unwedged Design, Type $R_{1}\left(c<n_{t}\right)$.

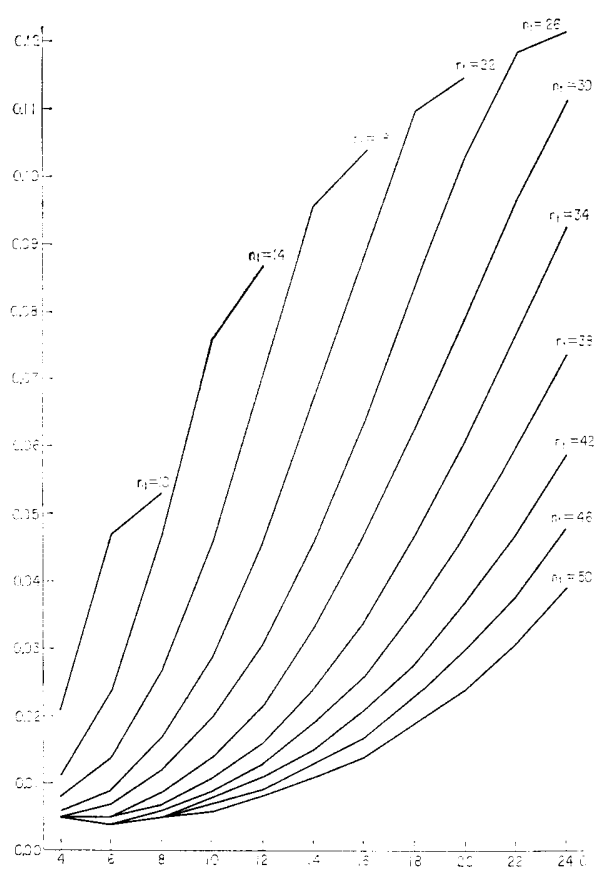

Fig. $\mathrm{VI}_{1} . \overline{\mathrm{ELOSS}} / \mathrm{NG}$, Unwedged Design, Type $L_{1}\left(c<n_{t}\right)$.

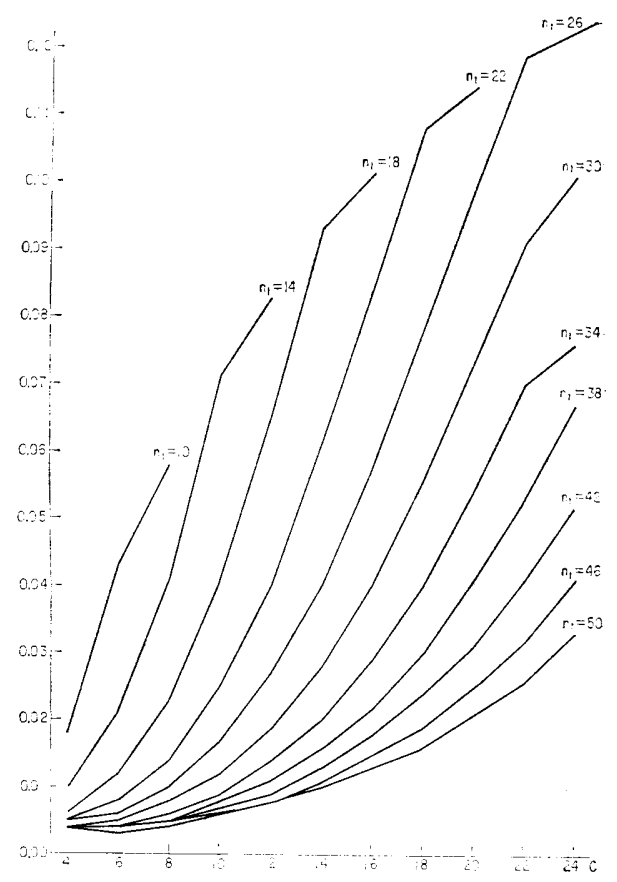

Fig. $\mathrm{VI}_{1}$. $\overline{\text { E LOSS }} / \mathrm{NG}$, Unwedged Design, Type $S_{1}\left(c<n_{t}\right)$.

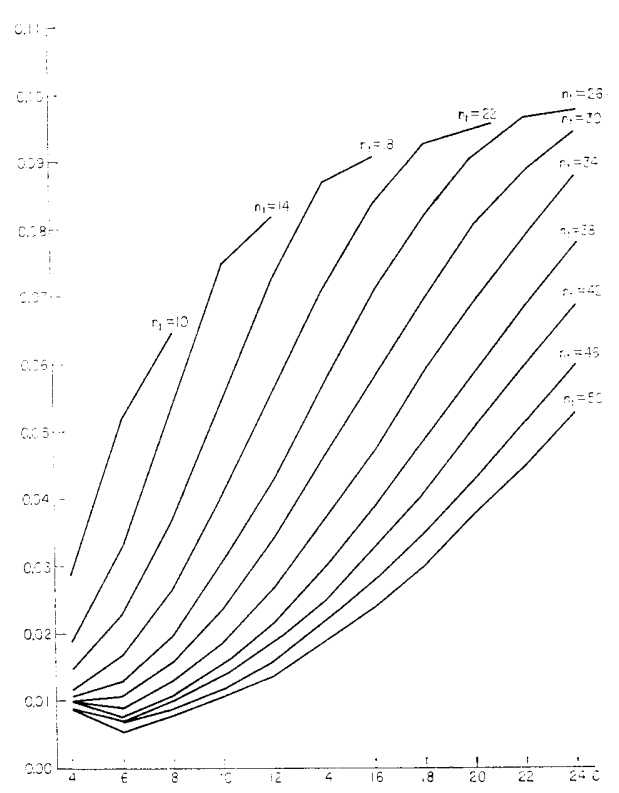

Fig. $\mathrm{VI}_{1}$. $\overline{\text { E LOSS }} / \mathrm{NG}$, Unwedged Design, Type $R_{2}\left(c<n_{t}\right)$. 


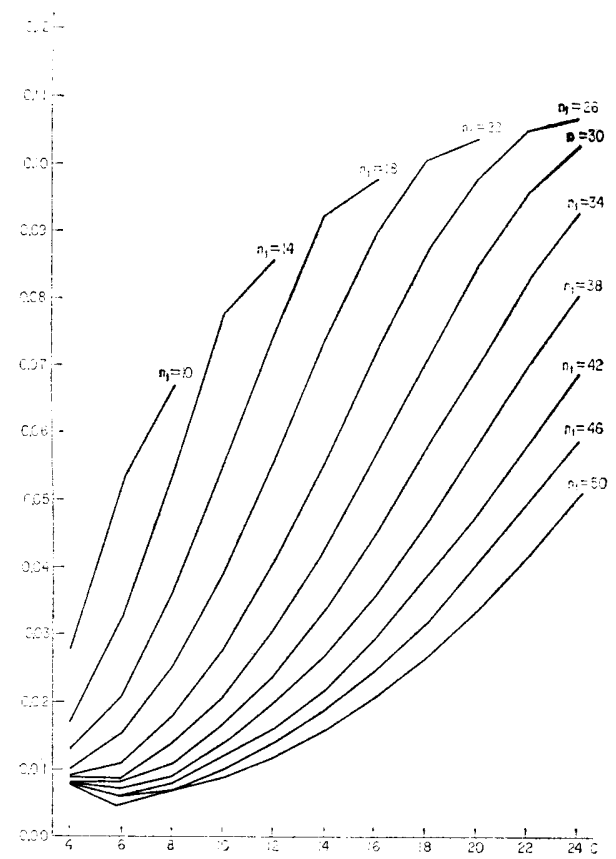

Fig. VI $_{1}$. $\overline{\text { E LOSS }} / \mathrm{NG}$, Unwedged Design, Type $S_{2}\left(c<n_{t}\right)$.

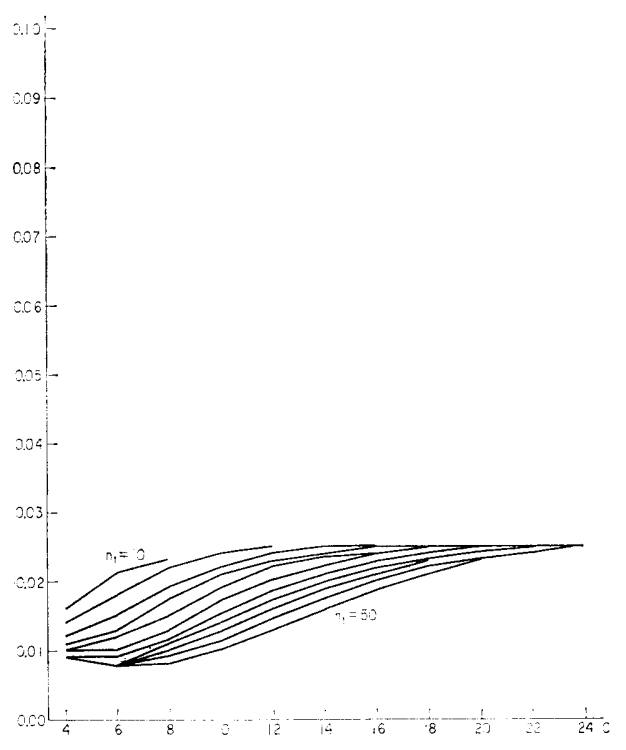

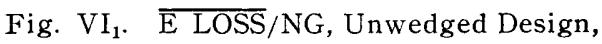
Type $R_{3}\left(c<n_{t}\right)$.

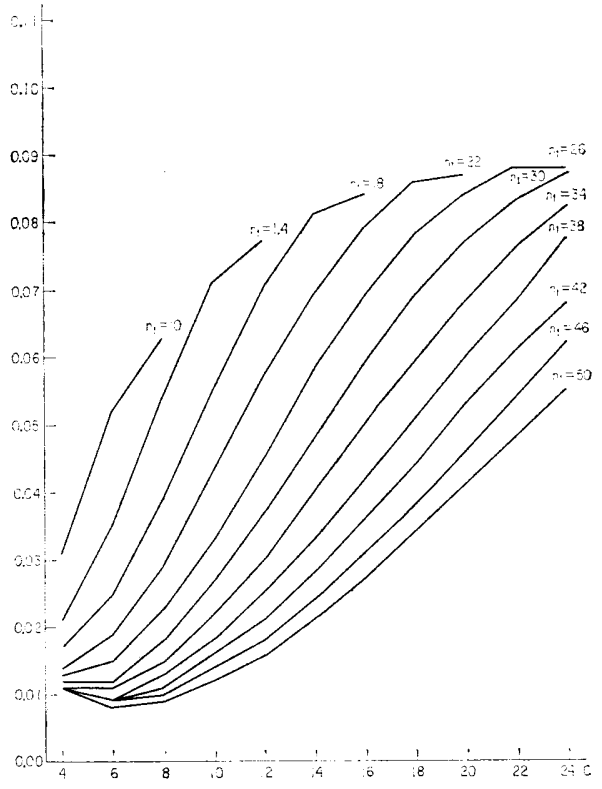

Fig. $\mathrm{VI}_{1} . \overline{\mathrm{ELOSS}} / \mathrm{NG}$, Unwedged Design, Type $L_{2}\left(c<n_{t}\right)$.

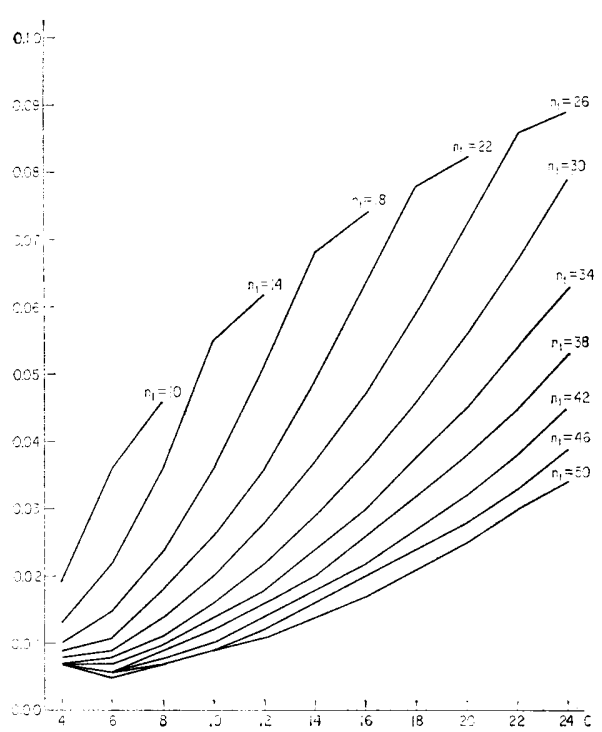

Fig. $\mathrm{VI}_{1}$. $\overline{\text { E LOSS }} / \mathrm{NG}$, Unwedged Design, Type $S_{4}\left(c<n_{t}\right)$. 


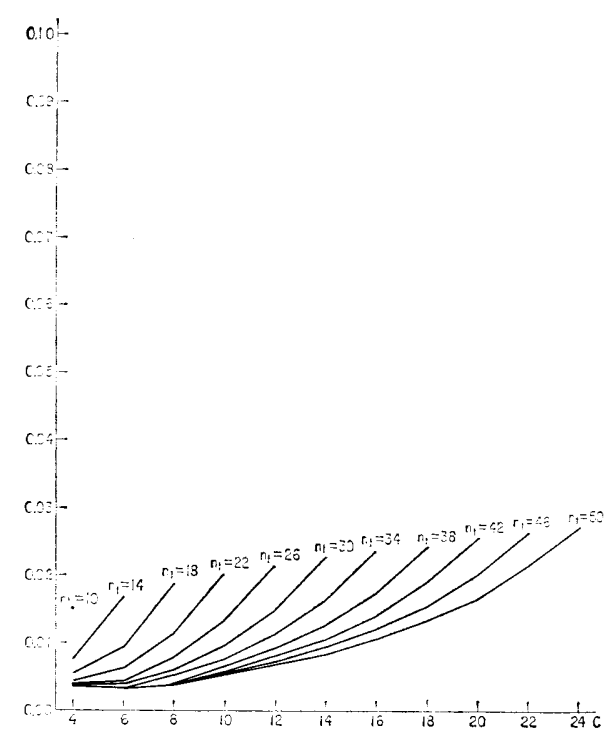

Fig. $\mathrm{VI}_{2} . \quad \overline{\mathrm{E} \text { LOSS }} / \mathrm{NG}$, Wedged Design, Type $R_{1}\left(2 c<n_{t}\right)$.

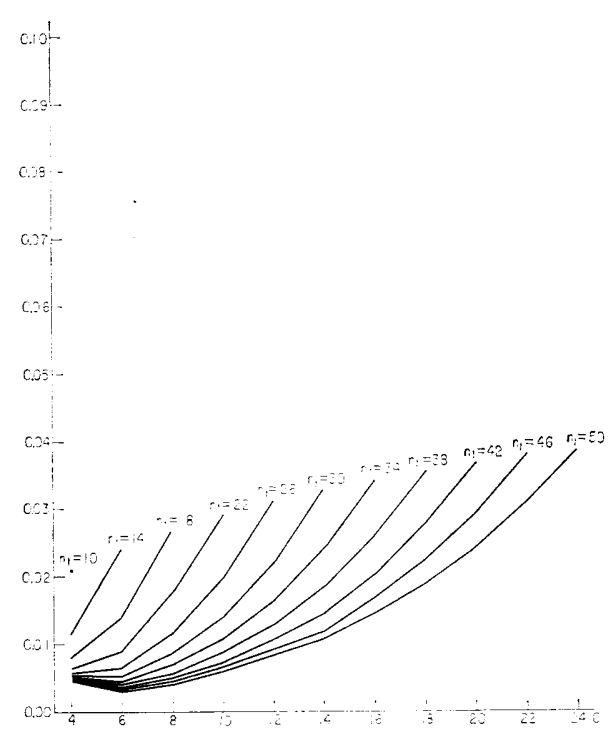

Fig. $\mathrm{VI}_{2} \cdot \overline{\mathrm{ELOSS}} / \mathrm{NG}$, Wedged Design, Type $L_{1}\left(2 c<n_{t}\right)$.

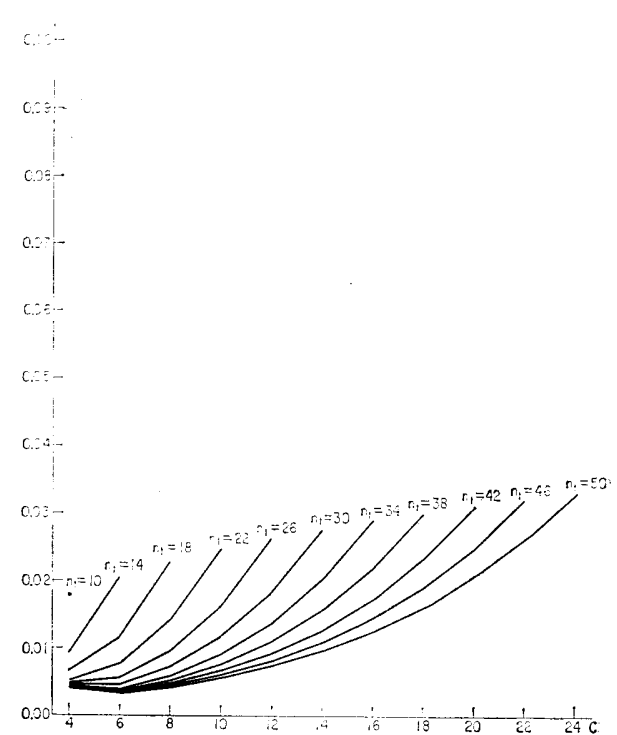

Fig. $\mathrm{VI}_{2} \cdot \overline{\mathrm{E} \mathrm{LOSS}} / \mathrm{NG}$, Wedged Design, Type $S_{1}\left(2 c<n_{t}\right)$.

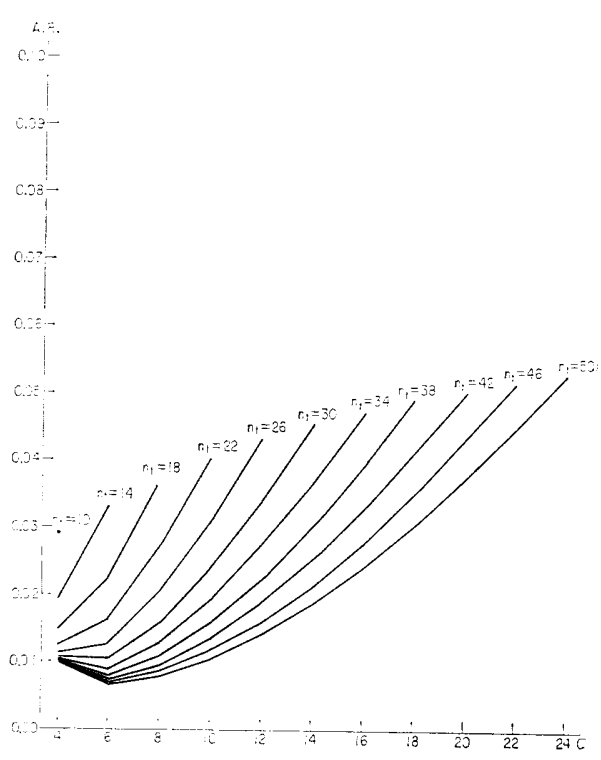

Fig. $\mathrm{VI}_{2}$. $\overline{\text { E LOSS } / N G, ~ W e d g e d ~ D e s i g n, ~}$ Type $R_{2}\left(2 c<n_{t}\right)$. 


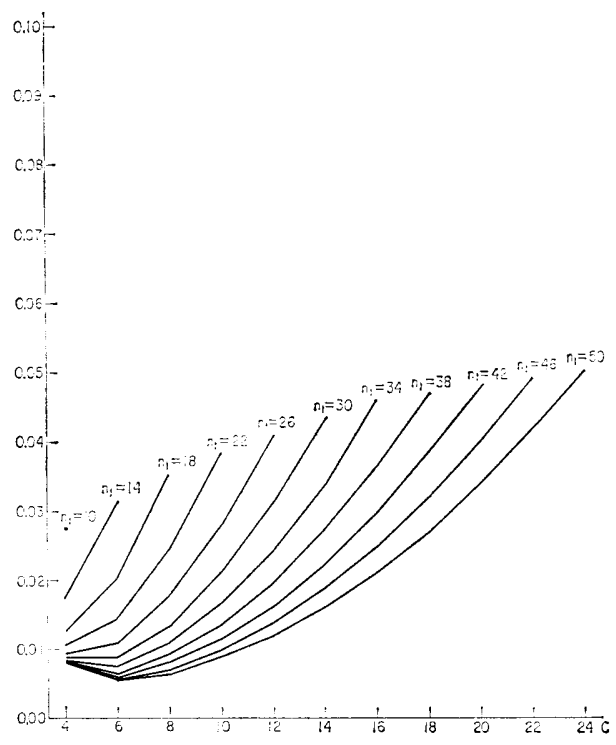

Fig. $\mathrm{VI}_{2}$. $\overline{\text { E LOSS }} / \mathrm{NG}$, Wedged Design, Type $S_{2}\left(2 c<n_{t}\right)$.

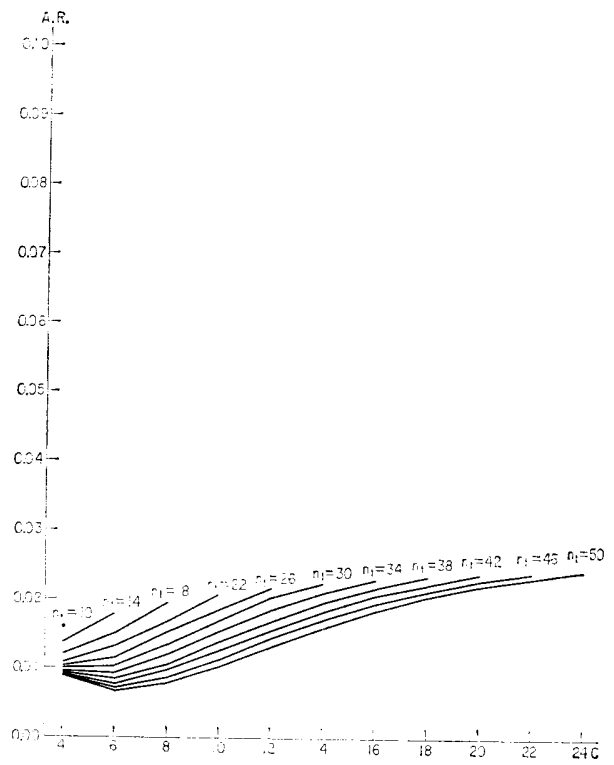

Fig. $\mathrm{VI}_{2}$. $\overline{\mathrm{E} \text { LOSS}} / \mathrm{NG}$, Wedged Design, Type $R_{3}\left(2 c<n_{t}\right)$.

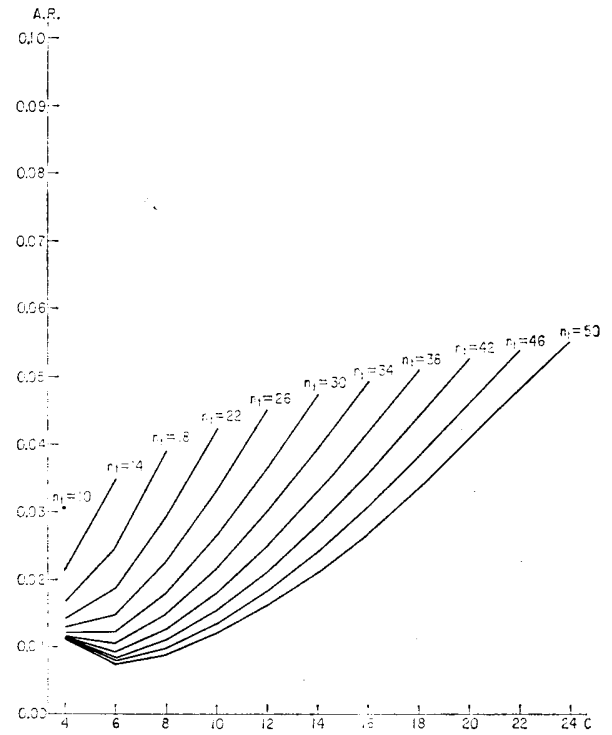

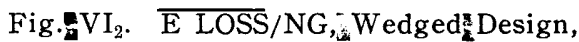
Type $L_{2}\left(2 c<n_{t}\right)$.

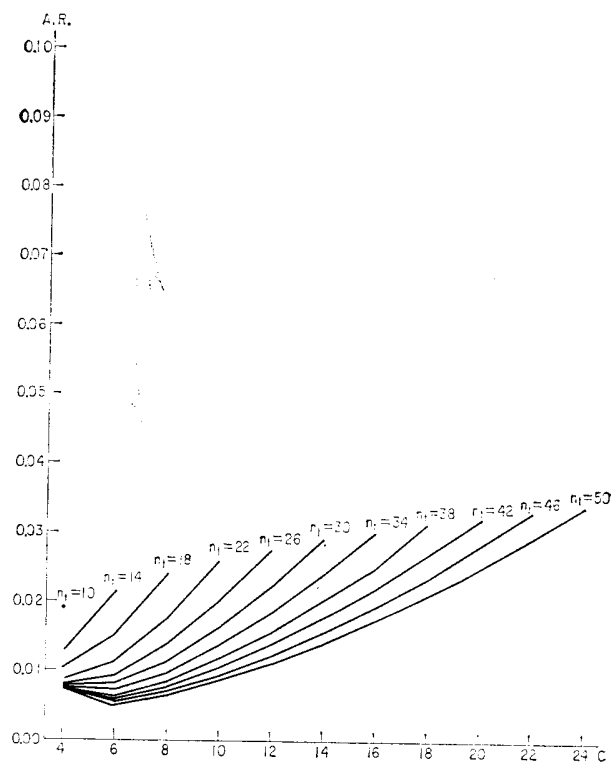

Fig. $\mathrm{VI}_{2} . \overline{\mathrm{E} \text { LOSS }} / \mathrm{NG}$, Wedged Design, Type $S_{4}\left(2 c<n_{t}\right)$. 


\section{References}

[1] Armitage, P., "Restricted Sequential Procedure", Biometrika, 44, 9-26 (1957).

[2] Armitage, P., “Sequential Medical Trials", Blackwell Scientific Publications, Oxford, England (1960).

[ 3 ] Bross, I., "Sequential Medical Plans", Biometrics, 8, 188-205 (1952).

[4] Choi, S.C., "Truncated Sequential Designs for Clinical Trials based on Markov Chains", Biometrics, 24, 159-166 (1968).

[5] Colton, T., "A Model for Selecting One of Two Medical Treatments", J. Am. Stat. Assoc., 58, 388-400 (1963).

[6] Sugimura, M., "Optimum Designs for Selecting One of Two Medical Treatments, Fixed Sample Size Plan 1", Mem. Fac. Gen. Educ. Kumamoto Univ., Ser. Nat. Sci., 2, 1-7 (1967).

[7] Sugimura, M., “Optimum Designs for Selecting One of Two Medical Treatments, Fixed Sample Size Plan 2", Kumamoto J. Sci., Ser. A, 7, No. 4, 87-94 (1967).

[8] Sugimura, M. and Asano, C., "Optimum Designs for Selecting One of Two Medical Treatments, Fixed Sample Size Plan 3", Kumamoto J. Sci., Ser. A, 7, No. 4, 95-102 (1967).

[9] Sugimura, M., "Optimum Designs for Selecting One of Two Medical Treatments, Fixed Sample Size Plan 4.1", J. Kumamoto Women's Univ., 19, 67-71 (1967).

[10] Sugimura, M., "Optimum Designs for Selecting One of Two Medical Treatments, Fixed Sample Size Plan 5", J. Kumamoto Women's Univ., 20, 58-63 (1968).

[11] Sugimura, M. and Asano, C., "Optimum Designs for Selecting One of Two Medical Treatments, Sequential Plan 1", Bull. Math. Stat., 12, No. 3-4, 1-9 (1967).

[12] Sugimura, M., "Optimum Designs for Selecting One of Two Treatments, Sequential Plan 2", Kumamoto J. Sci., Ser. A, 8, No. 1, 11-19 (1967).

[13] Sugimura, M. and Asano, C., "Optimum Designs for Selecting One of Two Treatments, Fixed Sample Size Plan 6 and Sequential Plan 3", Kumamoto J. Sci., Ser. A, 8, No. 1, 21-57 (1967).

[14] Sugimura, M., "Optimum Designs for Selecting One of Two Treatments, General Considerations", Kumamoto J. Sci., Ser. A, 8, No. 2, 63-83 (1967).

[15] Sugimura, M., “Optimum Designs for Selecting One of Two Treatments, Fixed Sample Size Plan and Sequential Plan in a Population with One Parameter Exponential Distribution", Bull. Math. Stat., 13, No. 1-2, 1-23 (1968).

[16] Sugimura, M., Goto, M. and Asano, C., "Optimum Sequential Designs Based on Markov Chains for Selecting One of Two Clinical Treatments", Mem. Fac. Engrg. Kumamoto Univ., XV, No. 3, 1-16 (1969).

[17] Sugimura, M., Goto, M. and Asano, C., "Some Sequential Designs Based on Markov Chains for Selecting One Two Medical Treatments". J. Kobe Univ. of Mercantile Marine, 19, 159-172 (1971).

[18] Wald, A., “Sequential Analysis, John Wiley and Sons: New York (1947). 